\title{
GEOLOGÍA DE LAS ISLAS CHAFARINAS
}

\author{
ANTONIO PINEDA Y JOSÉ LUIS BARRERA \\ Ilustre Colegio Oficial de Geólogos
}

\section{FISIOGRAFÍA DE LAS ISLAS Y SU ENTORNO}

\section{Las islas}

Las tres islas Chafarinas (Congreso, Isabel II y Rey Francisco o Rey, nombradas de oeste a este), se inscriben dentro de un área de 2,4 por $1 \mathrm{~km}$, con una superficie conjunta de $0,75 \mathrm{~km}^{2}$. Están situadas entre los paralelos $35^{\circ} 10^{\prime}$ y $35^{\circ}$ $11^{\prime}$ de latitud norte, y los mer idianos $2^{\circ} 24^{\prime}$ y $2^{\circ} 27^{\prime}$ de long itud oeste. En general, presentan una topografía suave que contrasta con la costa acantilada que las limitan.

La isla del Congreso tiene una forma irregular y es la mayor y más occidental, con $1.009 \mathrm{~m}$. de longitud, en dirección norte-sur, un perímetro de 3,4 km. y una cota máxima de 137 metıos (cerro Nido de las Águilas). La pendiente general dominante es hacia el este y los acantilados, los más impor tantes del archipiélago, alcanzan alturas de 20-50 m. y, excepcionalmente, más de 100 m.

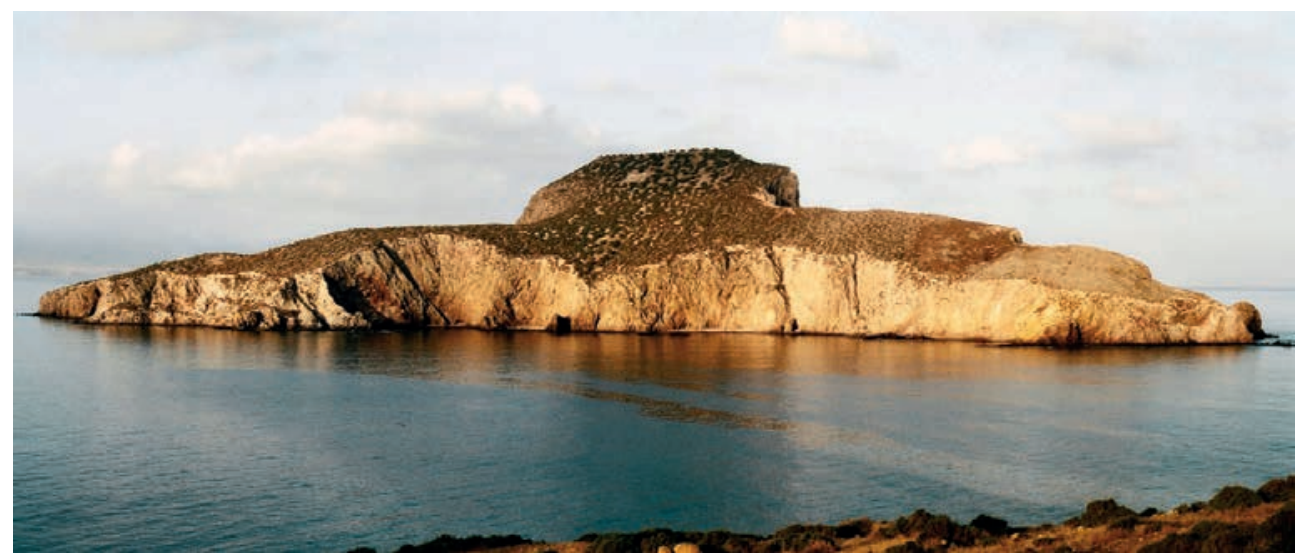

La isla del Congreso, vista desde el este, desde Isabel II. Nótese la existencia de una suave ladera alta, cortada abruptamente por los acantilados. 
La isla de Isabel II está situada a $800 \mathrm{~m}$ al este del Congreso. Es de contorno sensiblemente circular, y mucho más baja y plana, con $2 \mathrm{~km}$ de perímetro, 35 $\mathrm{m}$ de cota máxima y una ladera dominante inclinada hacia el sureste. Sus costas son acantiladas bajas (8-15 m.), siendo la única que tiene un puer to de atraque para barcos medianos y pequeños, así como una pob lación humana constante, representada por una reducida guarnición militar y el per sonal adscrito a una estación biológica dependiente del Ministerio de Medio Ambiente.

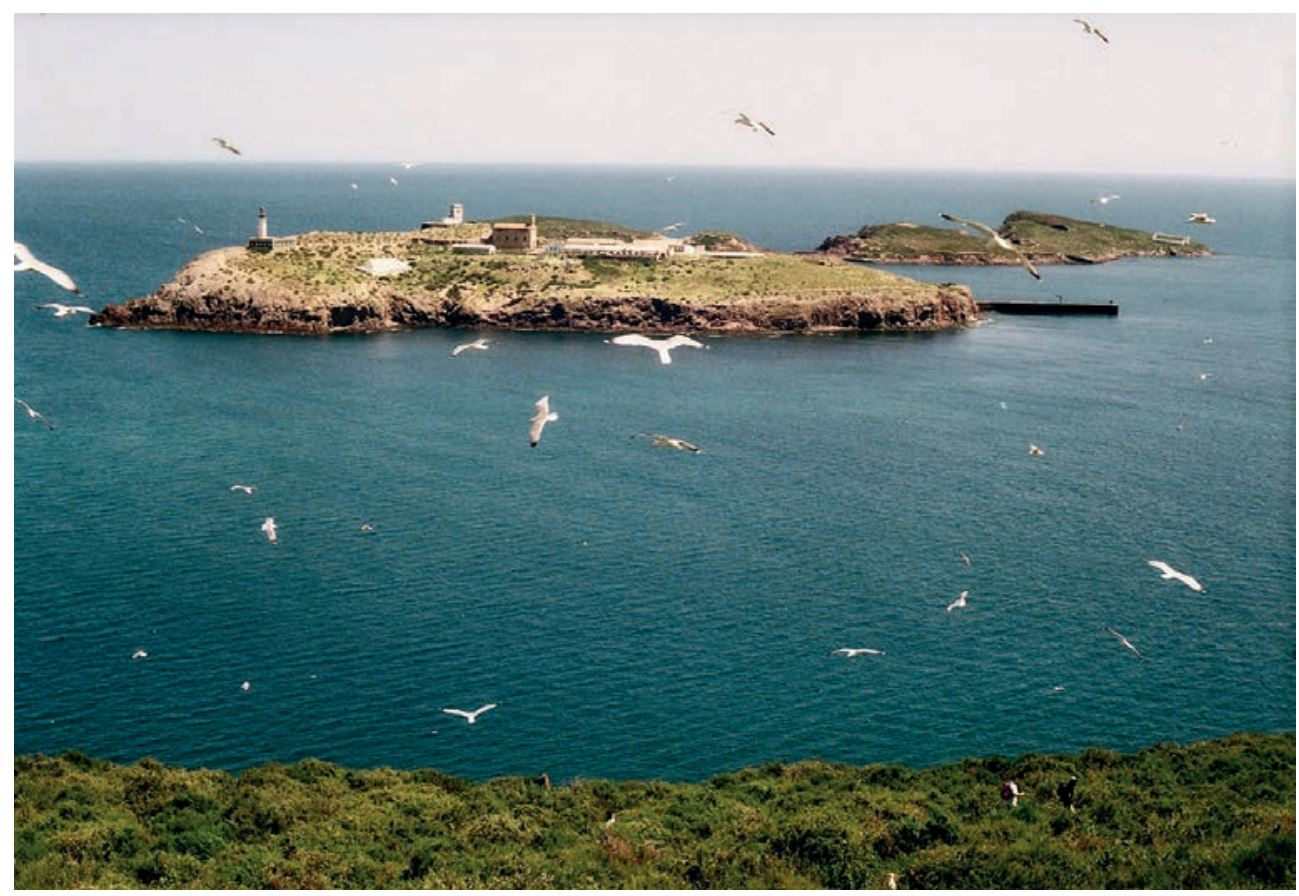

La isla de Isabel II, vista desde el oeste, desde la del Congreso. Detrás aparece la del Rey.

La isla del Rey es la menor y más alargada, con forma de semiluna abierta a oriente. Topográficamente presenta una única ladera descendente al oeste, limitada por unas costas acantiladas, la oriental de altura media (10-15 m.) y la occidental baja (4-6 m.). Es la que contiene el cementerio del archipiélago. Por erosión litoral, está a punto de ser estrangulada y dividida en dos, habiéndose construido un muro para evitar el paso del oleaje oriental a la costa occidental, durante los temporales. 


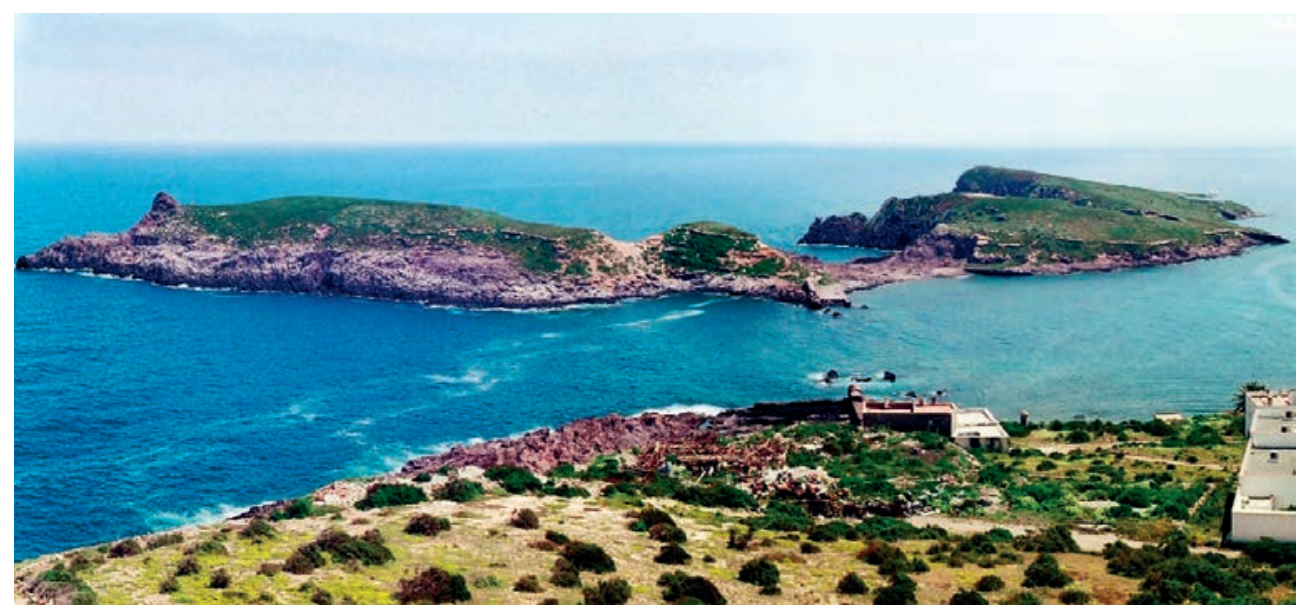

La isla del Rey, vista desde el Oeste, desde Isabel II.

Desde finales del siglo XIX se proyectó la unión física de la isla del Rq con la de Isabel II, mediante un dique. Este dique ter minó de construirse en 1910 pero fue destruido por un temporal en 1914, no volviéndose a reconstruir.

Conviene indicar que no existen recursos naturales en las islas, ni siquiera de agua, que debe obtenerse por otros medios.

\section{Los fondos marinos próximos}

Las islas se encuentran en el borde de una amplia pla taforma marina de poca profundidad, de unos 8-9 m. en los $2 \mathrm{~km}$.más próximos a la costa,y de 12 $15 \mathrm{~m}$. en la par te más cercana a las islas. La plataforma es fangosa, debido a la proximidad del río Muluya. En el límite norte de la plataforma, donde se asientan las islas, las paredes rocosas descienden verticalmente desde los doce hasta los cincuenta metros.

Los freus o canales que separan las islas entr e sí tienen una profundidad escasa (14-35 m. entre Congreso e Isabel II, y 5-8 m. entre Isabel II y Re y), existiendo un promontorio rocoso muy marcado (La Laja, a tan solo $3 \mathrm{~m}$. de profundidad) en la parte norte del canal entre Congreso e Isabel II.

La disposición de las curvas batimétricas muestra que la isla del Congreso y La Laja constituyen una unidad morfológica, y la de Isabel II y del Re y, otra distinta. El canal entre ambas unidades se presenta con profundidades progresivamente crecientes hacia el norte, a manera de un antiguo valle sumergido. 


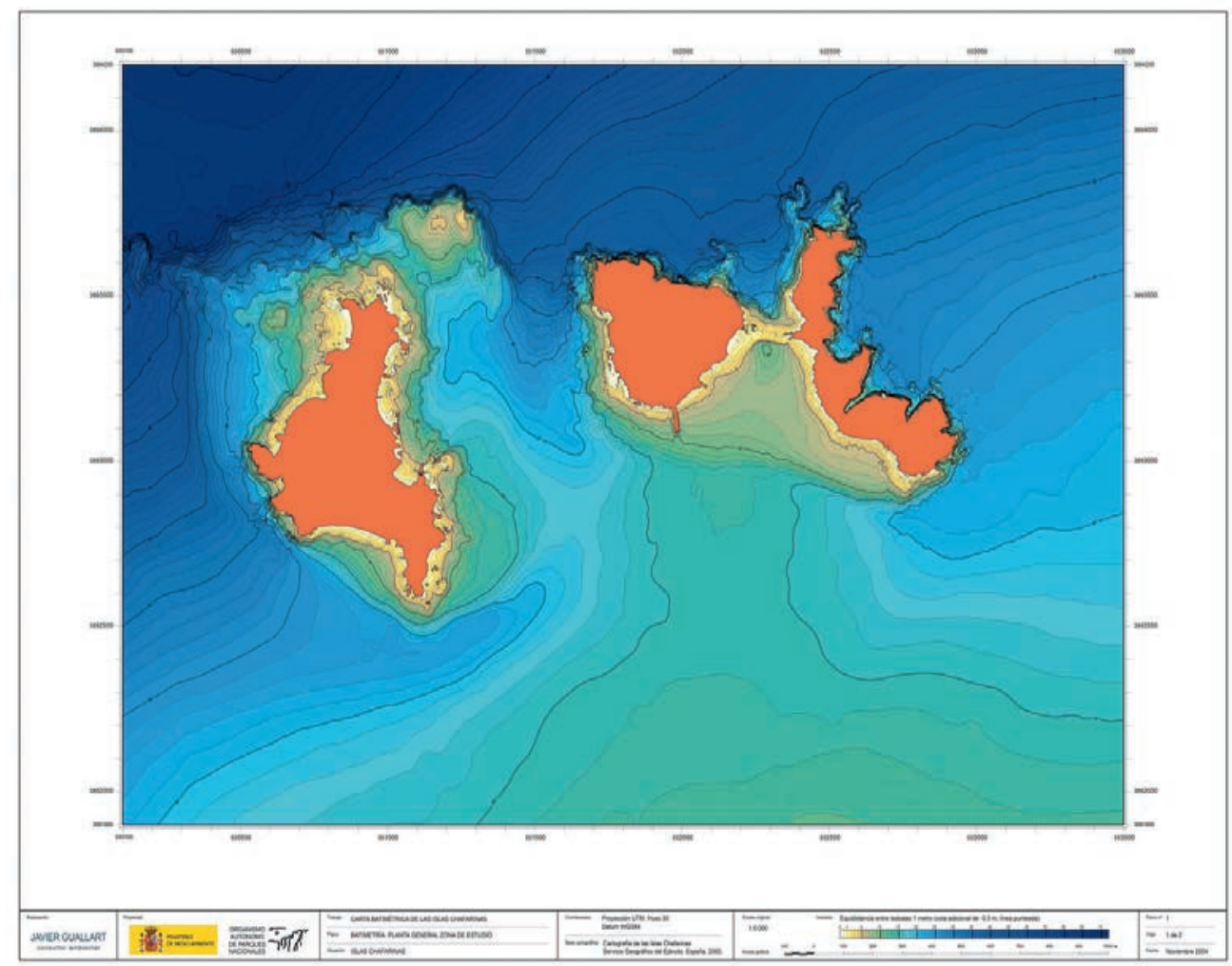

Carta batimétrica de las islas Chafarinas (J. Guallart). Fuente: Parques Nacionales (MARM).

\section{La costa norteafricana}

El accidente geográfico más marcado de la costa norteafricana cercana es el cabo del Agua, frente a las islas. Hacia el oeste, entre este cabo y el de Tres Forcas, la costa forma un amplio arco o golfo, en el que se localizan Melilla y la Mar Chica. Hacia el este y aproximadamente hasta el límite con Argelia, la costa dibuja un arco similar, que contiene la desembocadura del Muluya, el río mediterráneo más importante de Marruecos. Las islas se presentan, pues, justo enfrente del cabo más notable de un amplio sector del litoral norteafricano.

La costa es moderadamente acantilada (10-20 m.) en el cabo del Agua, descendiendo progresivamente hacia el este y el oeste, y pasando a costas bajas arenosas. 


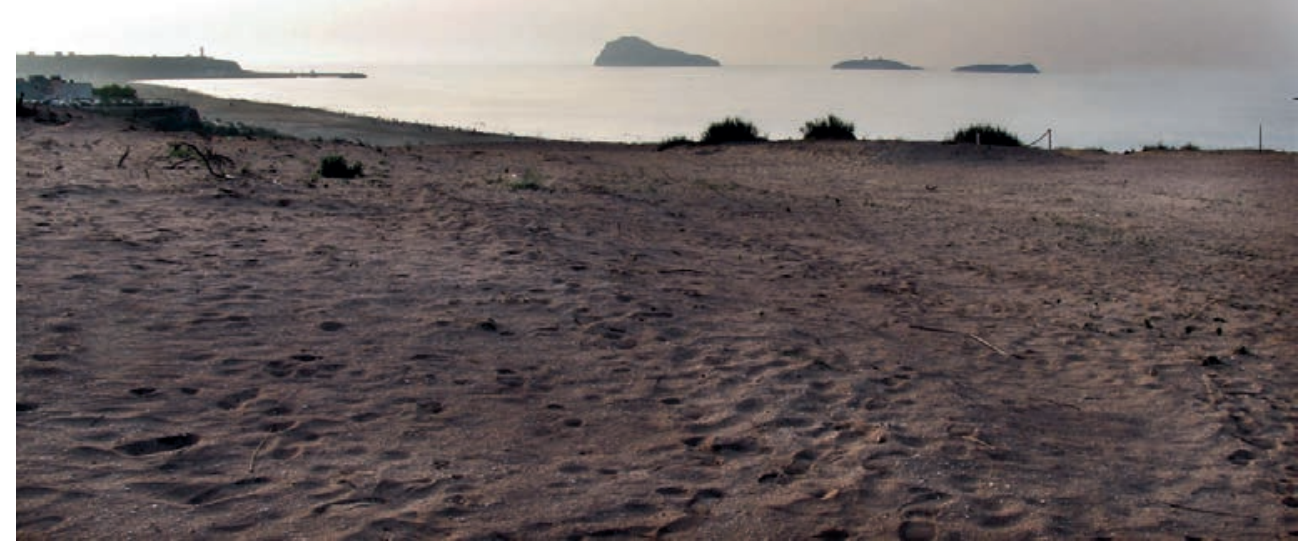

Islas Chafarinas al fondo, vistas desde la costa de cabo del Agua. Fuente: Antonio Ruiz

\section{GEOLOGÍA DE LA REGIÓN}

\section{El mar de Alborán, la Cordillera del Rif y su antepaís}

Las grandes unidades geológicas del entorno de las islas Chafarinas están representadas por el mar deAlborán, la terminación oriental de la Cordillera del Rif (desarrollada desde el estrecho de Gibraltar hasta el cabo Tres Forcas) y el antepaís rifeño (en la región continental, al sur de las Chafarinas).

La Cordillera del Rif conforma, con las Cordilleras Béticas del sur y sueste de España, la Cordillera Bético-rifeña. Esta Cordillera contornea, en su parte emergida, el mar de Alborán, por lo que sus estructuras experimentan una curvatura en la región del estrecho de Gibraltar, a la que se denomina Arco de Gibraltar. En la Cordillera Bético-rifeña se distinguen unas Zonas Externas y otras Internas, cuya diferencia es la presencia de afloramientos de zócalo paleozoico y de metamorfismo alpino, exclusivamente en las segundas.

Las Zonas Internas se presentan en las regiones costeras del mar deAlborán, así como en el fondo de éste , razones por las cuales han $r$ ecibido también el nombre de Dominio de Alborán. Además, el mar de Alborán es una región que presenta una corteza continental adelgazada, de unos $12 \mathrm{~km}$. de espesor, lo que contrasta con el engrosamiento de la misma que presentan sus bordes. 


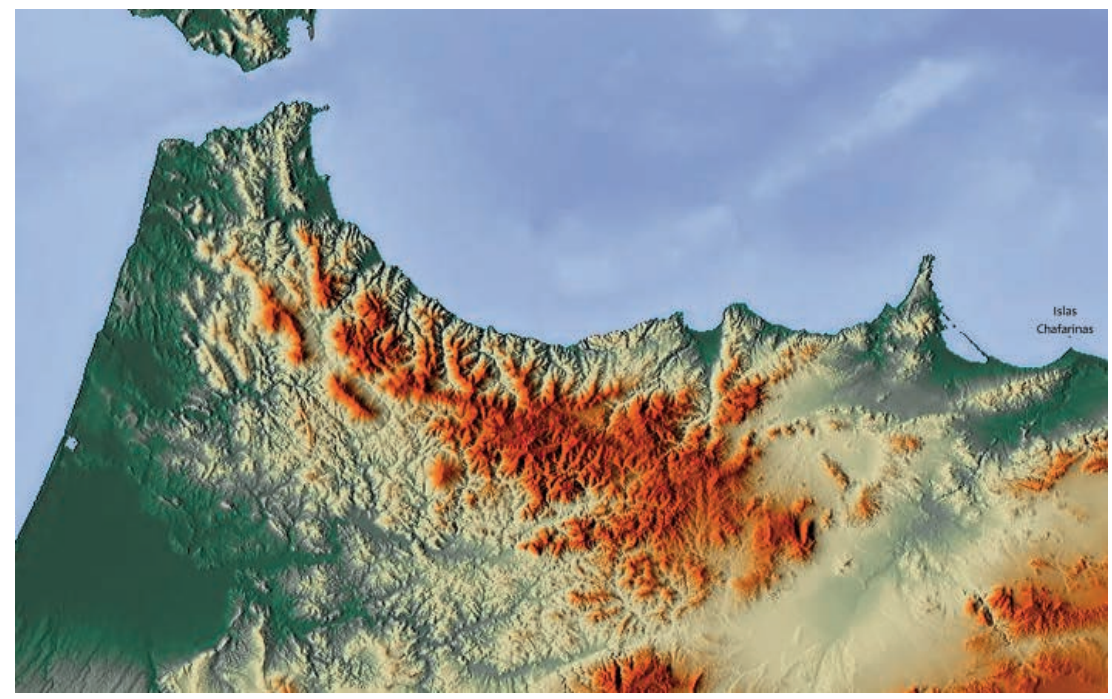

Cordillera del Rif y situación geográfica del archipiélago de las Chafarinas frente a la costa.

La Cordillera Bético-rifeña se supone generada, durante el Terciario, por el desplazamiento hacia el oeste del Dominio de Alborán (considerado, pues, como una placa tectónica independiente) y el poster ior encajamiento de éste entre las placas mayores ibérica y africana, lo que habría dado lugar al Arco de Gibraltar. No obstante, hay alguna hipótesis alternativa que le relacionan con la interacción de la falla transformante Azores-Gibraltar respecto de la extensión cortical del mar o Dominio deAlborán, asumiendo que éste pueda ser una parte meridional de la placa ibérica.

El antepaís rifeño (placa africana), al sur de las Chafarinas, está constituido por sierras de materiales mesozoicos aflorantes según fallas NE-SO, entre las que se disponen cuencas y formaciones sedimentarias de edad terciaria y cuaternaria.

\section{El volcanismo neógeno y cuaternario}

En la región (sobre todo, en la parte oriental de la Cordillera Bético-rifeña y del mar de Alborán) existen manifestaciones volcánicas que, aunque no activas en la actualidad, lo han sido desde el Neógeno hasta épocas geológicamente recientes (Cuaternario).

El volcanismo neógeno es el más importante volumétricamente. En la región costera marroquí se extiende desde Ras Tarf (al oeste de Melilla) hacia el este, y es de naturaleza calcoalcalina (con andesitas basálticas,andesitas y riolitas) 
o calcocalcalina potásica (con términos shoshoníticos, latitas y traquitas); el primero es el más antiguo (14-9,8 Ma) y occidental,y el segundo más reciente (9$5,4 \mathrm{Ma}$ ) y or iental. En el sur este de España, hay un volcanismo similar en las regiones de cabo de Gata (calcoalcalino) y Níjar-V era-Mazarrón-Cartagena (calcoalcalino potásico).

El volcanismo plio-cuaternario $(5,6-1,5 \mathrm{Ma})$ es de na turaleza basálticoalcalina, pudiendo superponerse al anterior, a veces sobre sus mismos centros de emisión (como en el monte Gurugú, junto a Melilla). No es exclusivo de la región ya que se encuentran manifestaciones del mismo más al suroeste (según las directrices de fractura NE-SO del Atlas) y al noreste (Cartagena, Cofrentes, Olot).

$\mathrm{Al}$ volcanismo calcoalcalino y calcoalcalino potásico se le ha supuesto elacionado con zonas de subducción de la cotteza del mar deAlborán bajo las placas continentales ibérica y africana, mientras que el basáltico alcalino se supone ascendido a favor de grandes fracturas corticales.

Las islas Chafarinas son una de las manifestaciones volcánicas de la región.

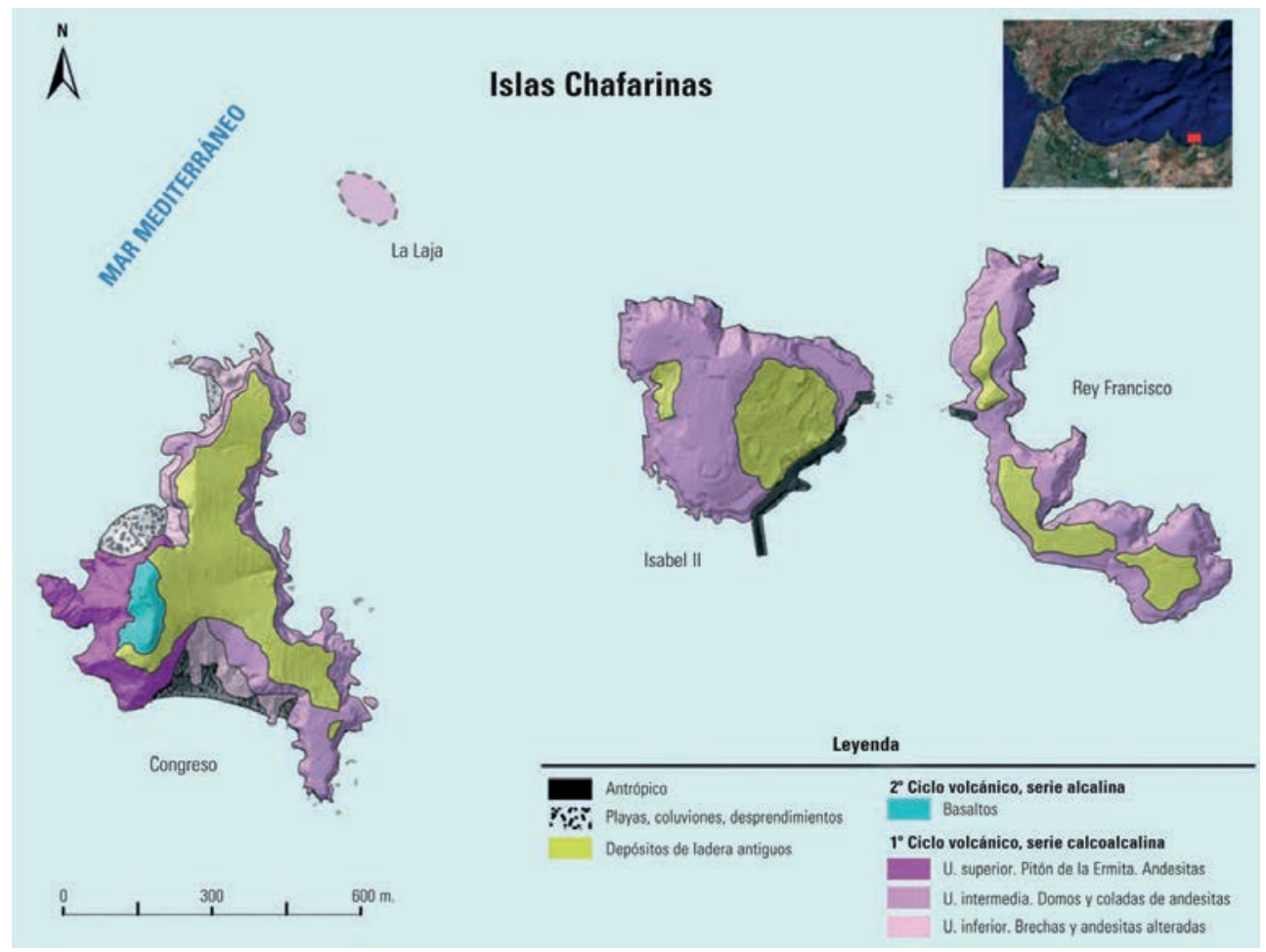

Mapa geológico de las islas Chafarinas (adaptado de A. Pineda, 2003). Fuente: MARM 


\section{HISTORIA DEL CONOCIMIENTO GEOLÓGICO DE LAS ISLAS}

Las primeras informaciones geológicas sobre las Chafar inas se deben al geólogo francés Charles Vélain que las publicó en 1874, después de un viaje que realizó por la costa norteafricana en el barco francés "Narval”, entre el cabo del Agua (Marruecos) y el cabo Negro (Túnez).

Posteriormente, el geólogo español Salvador Calderón hace el primer estudio petrográfico de muestras enviadas desde las islas, en 1894, y ofrece una clasificación petrológica, mencionando la existencia de capas calizas "marinas" (los niveles de costras, como se verá más adelante) en Isabel II y en la del Re y. Concluye, de manera acertada, que la litología volcánica de las islas Chafarinas es similar a la del sureste español. Sin embargo, el hecho de que no existan bombas o lapillis en todo el archipiélago y la existencia de las calizas "marinas" le lleva a concluir, erróneamente, que las islas son de origen submarino.

A principios de julio de 1905, el geólogo español Lucas Fernández Navarro visita las islas durante oc ho días, dentro del contexto de una expedición científica de la Real Sociedad Española de Histor ia Natural por las posesiones españolas del norte de África. Sus estudios suponen importantes avances estructurales, estableciendo tres niveles volcanoestratigráficos en las islas, y una cobertera de "travertino" calizo. Considera que las Chafarinas no son de origen submarino, sino un resto erosivo de un macizo volcánico de importancia mucho mayor.

En la primera mitad de 1921, Agustín Marín Bertrán de Lis viaja a las islas y estudia muestras volcánicas, en el contexto de los estudios geológicos que realizaba en el Protectorado Español la Comisión de Estudios Geológ icos de Marruecos. Considera que las islas no son de or igen submarino, sino debidas al enfriamiento lento de un único macizo, posteriormente dislocado por la erosión y la tectónica.

En 1998, geólogos y biólogos de las Univ ersidades de Huelva y Se villa (Rodríguez Vidal et al.) publican un estudio del Medio Físico del arc hipiélago, aportando datos estructurales de la fracturación frágil y del flujo magmático en las tres islas, y una primera cartografía geológica del archipiélago, realizada para el organismo Parques Nacionales, también aportan estudios y dataciones sobre las formaciones cuaternarias de las islas.

Finalmente, las islas Chaf arinas son incluidas dentr o del Plan MA GNA (Mapa Geológico Nacional) del Instituto Geológico y Minero de España, reali- 
zándose su cartografía geológica a escala 1/5.000, y sus correspondientes estudios petrográficos y sedimentológicos (Pineda y Barrera, 2003). Este estudio es la base de algunos artículos aparecidos posteriormente (Pineda y Barrera, 2004; Barrera y Pineda, 2006), el segundo de los cuales inclue esquemas cartográficos en colores de las tres islas.

\section{Presentación geológica y geomorfológica de las islas}

Las islas Chafarinas están constituidas fundamentalmente por rocas volcánicas que, por sus características petr ológicas, y aun a pesar de la car encia de dataciones absolutas, pueden ser asimiladas a los v olcanismos neógeno (calcoalcalino) y pliocuaternario (alcalino) descritos anteriormente. Es importante resaltar que en la $\mathrm{r}$ egión norteafricana cercana, no se encuentran rocas volcánicas en más de $25 \mathrm{~km}$. a la redonda de las islas.

Sin embargo, las islas no exhiben una morfología volcánica, debido a la actuación de los procesos erosivos tras el cese de las erupciones. Las islas presentan una morfología superior relativamente suave (laderas altas, con algunas pequeñas vaguadas), cortada abruptamente por los acantilados actuales (Fotografía 1).

Estas laderas altas se inclinan fundamentalmente hacia el inter ior del archipiélago. Concretamente, en la isla del Congreso descienden dominantemente hacia el este (y también un poco hacia el oeste, en su parte más alta); en Isabel II hacia el sureste (y oeste), y en la isla del Rey hacia el oeste y suroeste. Esta suave y alta morfología insular constituye los restos de un relieve originalmente más extenso, quizá relacionado con un niv el del mar más bajo. En este sentido, las islas son a manera de cerros testigo de dicho relieve, cada vez con menos superficie debido a la acción erosiva marina, que modela y hace retroceder los acantilados. Las laderas altas comportan un tapiz sedimentario cuaternario, de importancia variable y de naturaleza subaérea.

Los acantilados, o los litorales abruptos bajo dichas laderas, también presentan depósitos cuaternarios, en este caso producto de la destrucción progresiva de los edificios insulares.

\section{El volcanismo de las Chafarinas}

En este capítulo se describirán las sucesiones, estructuras y petrografía de los materiales volcánicos de las islas. 


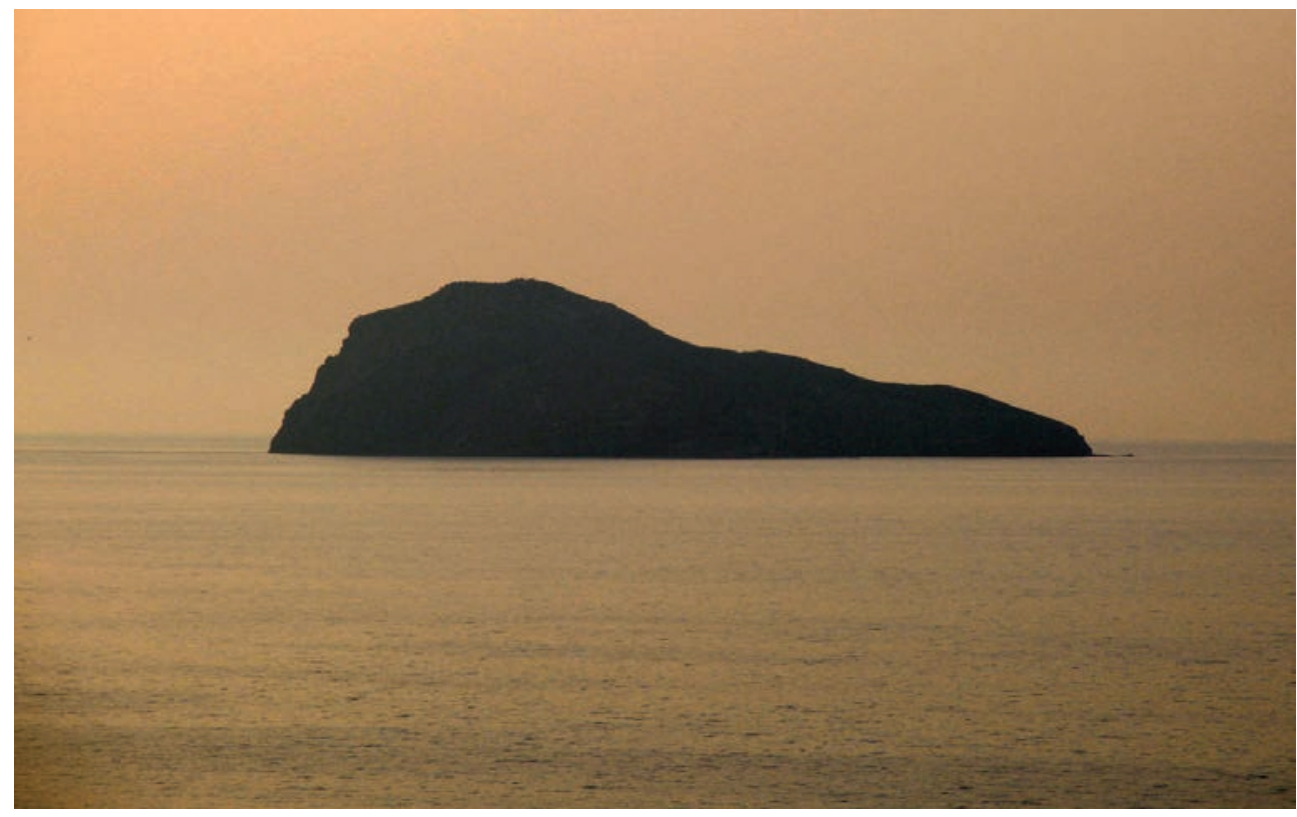

Perfil de la isla del Congreso, desde la costa de Cabo del Agua, donde se aprecia la acusada inclinación de la ladera hacia el interior del archipiélago. Fuente: Antonio Ruiz

Los materiales atribuibles al Episodio calcoalcalino son de na turaleza andesítica y están pr esentes en las tr es islas. En la del Cong reso forman un apilamiento (es decir, una sucesión estratificada de coladas y niveles piroclásticos), en el que pueden distinguirse una Unidad inferior y otra superior, cortado por un pitón intrusivo (pitón de Punta de la Ermita). En las islas Isabel II y del Rey, las andesitas conforman un domo subvolcánico, probablemente contemporáneo con la Unidad superior del apilamiento del Congreso.

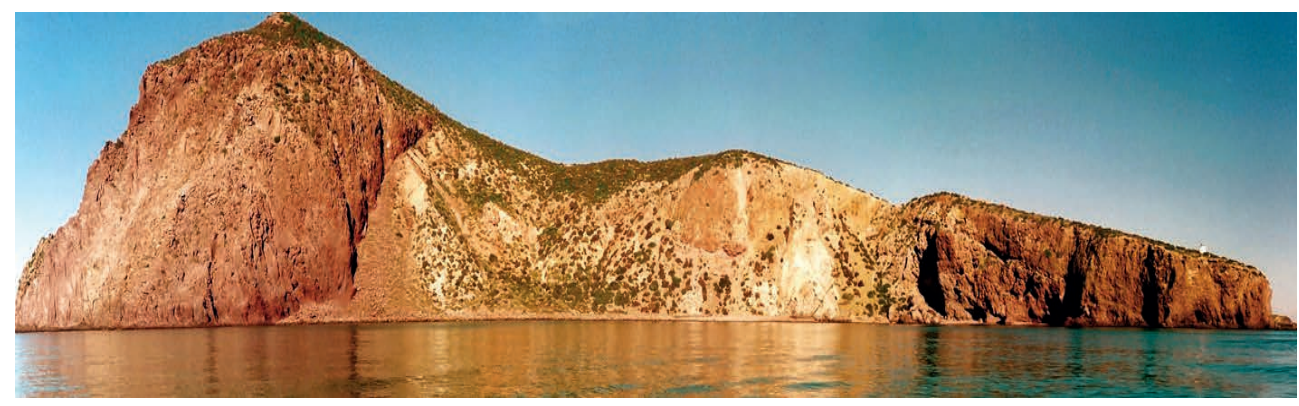

La isla del Congreso, vista desde el sur. Unidades calcoalcalinas inferior (en el centro) y superior (a la derecha). A la izquierda, el pitón intrusivo calcoalcalino de Punta de la Ermita. 
Los materiales basálticos del Episodio alcalino, solamente se encuentran en la parte más alta de la isla del Congreso, donde forman otro pequeño apilamiento.

\section{El apilamiento calcoalcalino de la isla del Congreso}

El apilamiento ocupa todo el centro y este de la isla,presentándose ligeramente inclinado hacia el ESE, lo que indica que los centros de emisión más importantes estaban localizados al oeste del actual edificio insular.

La Unidad volcanoestratigráfica inferior del apilamiento constituye la parte más baja de la isla, siendo sus mejores puntos de obser vación las laderas de playa Larga y la costa septentrional. Tiene unos 80-90 m. de espesor mínimo, y está compuesta por depósitos caóticos br echoides de tipo "debris avalanche”, con grandes bloques (algunos métricos) de rocas andesíticas s.l., a veces con colores claros, amarillentos o grises, y fuerte alteración hidrotermal, dentro de una matriz de tipo arenoso-arcilloso con cantos volcánicos. Estos depósitos pueden corresponder a grandes colapsos o derrumbes de los primeros edificios volcánicos, tal vez domáticos, surgidos en el ár ea. Asociados a estos depósitos se presentan coladas andesíticas junto a las playas Larga y de la Sangre, en el sur y noroeste de la isla. Estas coladas pueden contener encla ves de tipo cor neánico con una clara textura granoblástica de recristalización.

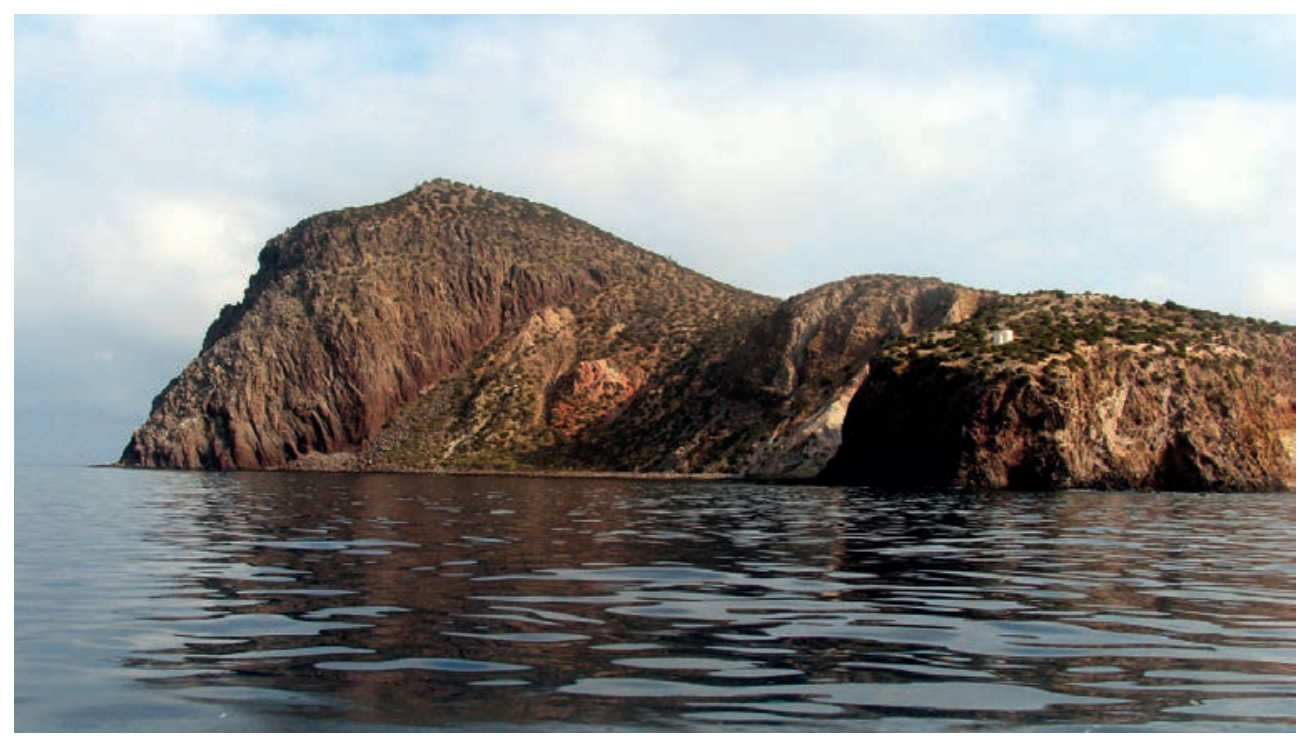

Vista de las laderas de playa Larga al sur de la isla. Fuente: Eduardo Bilbao 
La Unidad superior recubre a la anterior, pudiendo ser obser vada en los acantilados orientales y noroccidentales de la costa. La Unidad super ior es de colores más oscuros (grises, a veces con tonos rojizos) que la inferior; estando constituida por rocas masivas y rocas brechoides. Las rocas masivas muestran, a veces, disyunción columnar generalmente sub vertical, representando entonces diques o conductos de emisión subvolcánicos de tamaño decamétrico. Las rocas brechoides están formadas por grandes bloques, métricos o mayores, de andesitas con escasa matriz y pueden ser inter pretadas como brechificación autoclástica de las partes emitidas por los conductos anter iores. Las rocas de esta unidad suelen contener enclaves de tamaño decimétr ico, algunos de tipo diabásico o piroxenítico. El espesor visible mínimo para esta unidad (de la que no se conoce su techo, erosionado) es de unos 90-100 m.

Petrográficamente, todas las r ocas volcánicas de este apilamiento son andesitas porfídicas, con textura fluidal y grado variable de alteración, constituidas por fenocristales de plagioclasa de 0,4-2,7 mm. de tamaño, biotita generalmente oxidada (0,3-2,7 mm), clinopiroxeno (0,4-1,8 mm.), anfíbol con grado variable de conser vación y apa tito accesorio $(0,2-1 \mathrm{~mm}$.), en una ma triz criptocristalina.

Los materiales calcoalcalinos del apilamiento de la isla del Cong reso se presentan atravesados por diques (cor respondientes al Episodio alcalino suprayacente, por lo que se describen más adelante) y afectados por fracturas.

Las fracturas son generalmente de tipo distensiø, reconociéndose dos sistemas predominantes (NNO-SSE y ENE-OSO), con saltos de magnitud métrica. El sistema NNO-SSE tiene inclinación $50^{\circ}-75^{\circ}$ al oeste y es observable en la costa oriental (Cuevas de Lara) y en la parte norte de la isla,habiendo influido en el modelado del acantilado. El sistema ENE-OSO, probablemente con labio hundido norte, se presenta en la parte oriental de playa Larga y en algunos puntos de la costa oriental.

\section{El pitón calcoalcalino de Punta de la Ermita, en la isla del Congreso}

La Unidad intrusiva de Punta de la Ermita forma la parte más occidental, también acantilada, de la isla del Congreso. Está constituida por un pitón de unos $350 \mathrm{~m}$ de diámetro, que presenta disyunción columnar vertical y corta las unidades volcanoestratigráficas descritas, sobre todo, la inferior. La roca es de tipo andesítico masivo, con tonos g rises a rosados, petrográficamente similar a las andesitas de la Unidad superior, pero con menor tamaño de grano. 


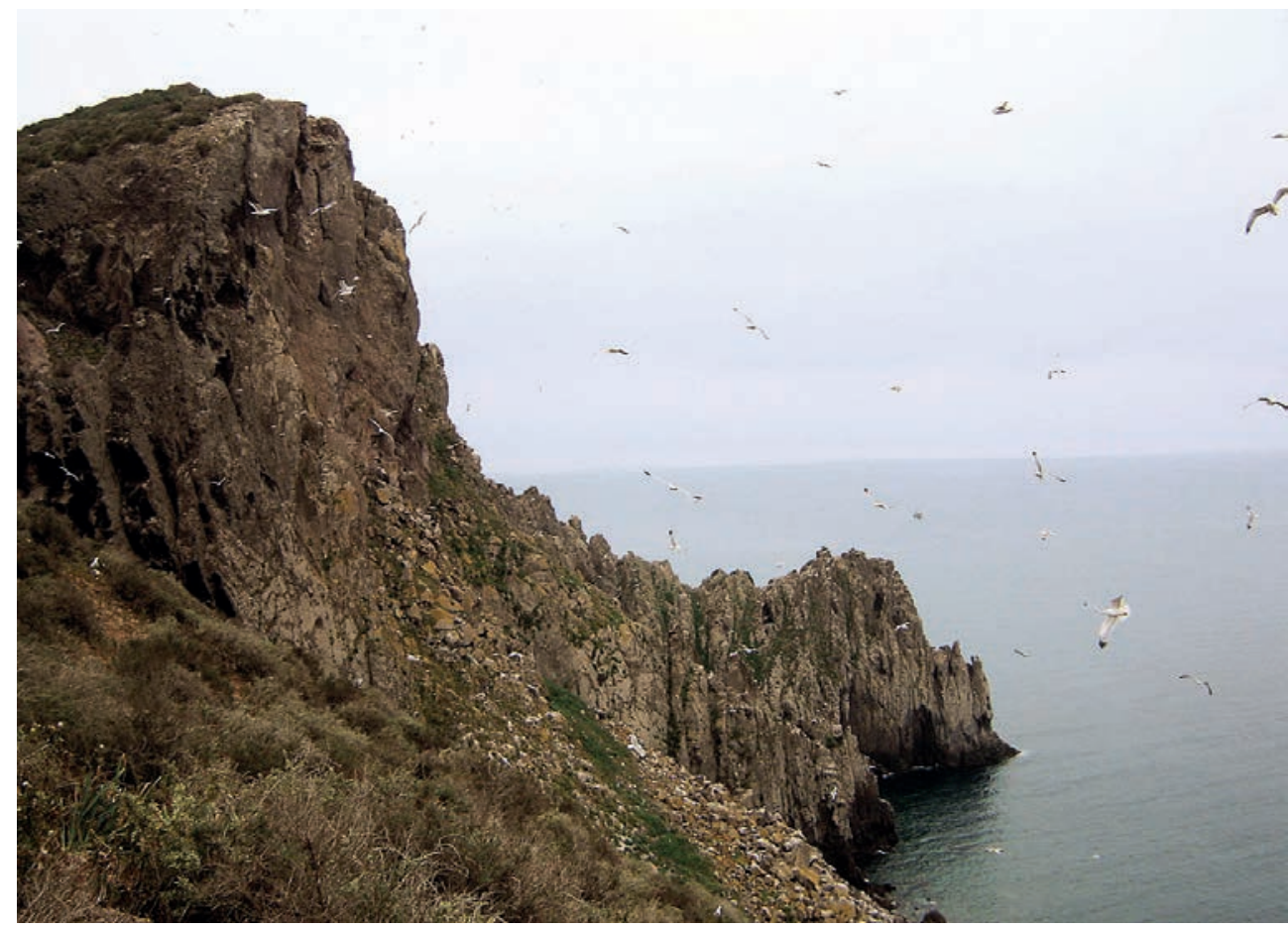

Pitón calcoalcalino de Punta de la Ermita. Fuente:Alexandre Lorenzetto

\section{El domo calcoalcalino de la isla de Isabel II y del Rey}

Las islas de Isabel II y del Rey están constituidas por un único tipo rocoso de andesitas masivas, grises o rojizas, con cristales de biotita, similares a las de la Unidad superior de la isla del Congreso, por lo que cabe suponerles contemporáneas con ella. Los mejores puntos de observación de estas rocas se localizan en la antigua cantera existente en la parte nororiental de la isla de Isabel II y en la parte centronorte de la isla del Rey, además de en las costas acantiladas de ambas Las rocas del promontorio submarino de La Laja son idénticas a las de estas islas.

Petrográficamente, estas andesitas son biotítico (¿anfibólicas?) con textura glomeroporfídica fluidal, matriz criptocristalina-afanítica y fenocristales de plagioclasa (80\%, con tamaños de 0,6-3,5 mm.), biotita oxidada (0,4-3,7 mm.) y clinopiroxeno prismático (0,6-1,9 mm.), así como apatito accesorio $(0,4-1,2$ $\mathrm{mm}$.). Se presentan con alto grado de oxidación y, en la parte central de la isla del Rey, con apreciable carbonatación.

En las andesitas de estas islas se encuentran encla ves de tamaño centidecimétrico de los siguientes tipos litológ icos (citados por orden de ma yor a 
menor abundancia): a) xenolitos de color gris-verdoso y grano fino, que corresponden a rocas pirometamorfizadas procedentes del sustrato cortical de las islas (son materiales plagioclásicos con textura g ranoblástica y posibles epidota, sillimanita y corindón accesorios); b) fragmentos de venas silíceo-carbonatadas, zonadas, como las que se describen más adelante; y c) fragmentos de andesitas como las que contienen los encla ves, si bien de distinto tamaño de g rano. Los mejores lugares para la observación y muestreo de enclaves son el extremo septentrional de la isla del Rey, y la cantera de Isabel II.

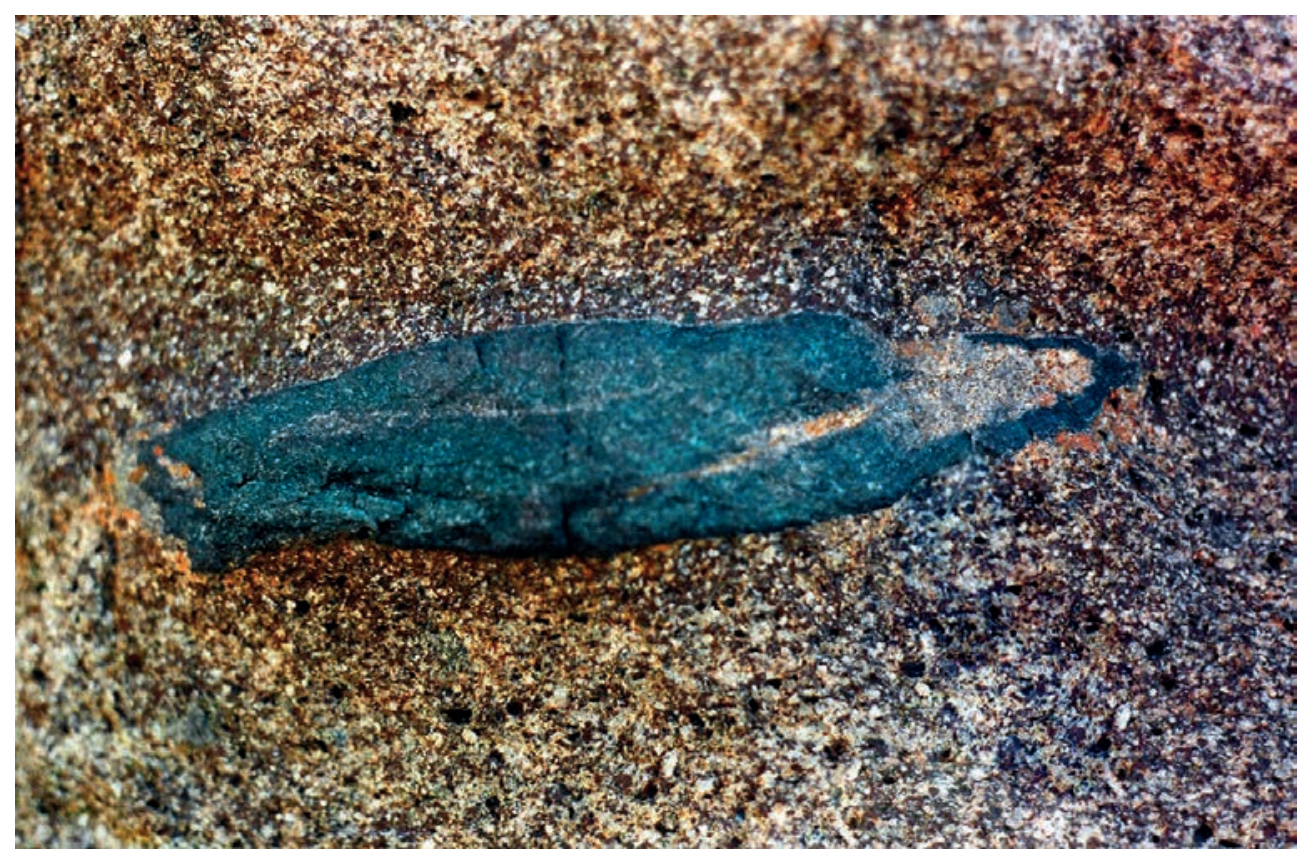

Enclave xenolítico en las andesitas del norte de la isla del Rey.

Las andesitas presentan estructuras de flujo magmático y disyunción columnar, generalmente perpendiculares o subperpendiculares entre sí. Las estructuras de flujo son planares y responden a variaciones en el tamaño de grano, o de la pr oporción de matriz vítrea, de las andesitas, así como a or ientación magmática de los fenocristales de las mismas.

De la similitud petrográfica entre ambas islas y, como se verá a continuación, de los datos estructurales de flujo y enfriamiento (disyunción columnar), se deduce que ambas islas conforman una única megaestructura domática (domo 
subvolcánico) erosionada. Ello estaría de acuerdo con los da tos batimétricos, según los cuales ambas islas constituy en una misma unidad morfológica. No se conservan restos de las rocas encajantes de este doma que habrían sido erosionadas posteriormente.

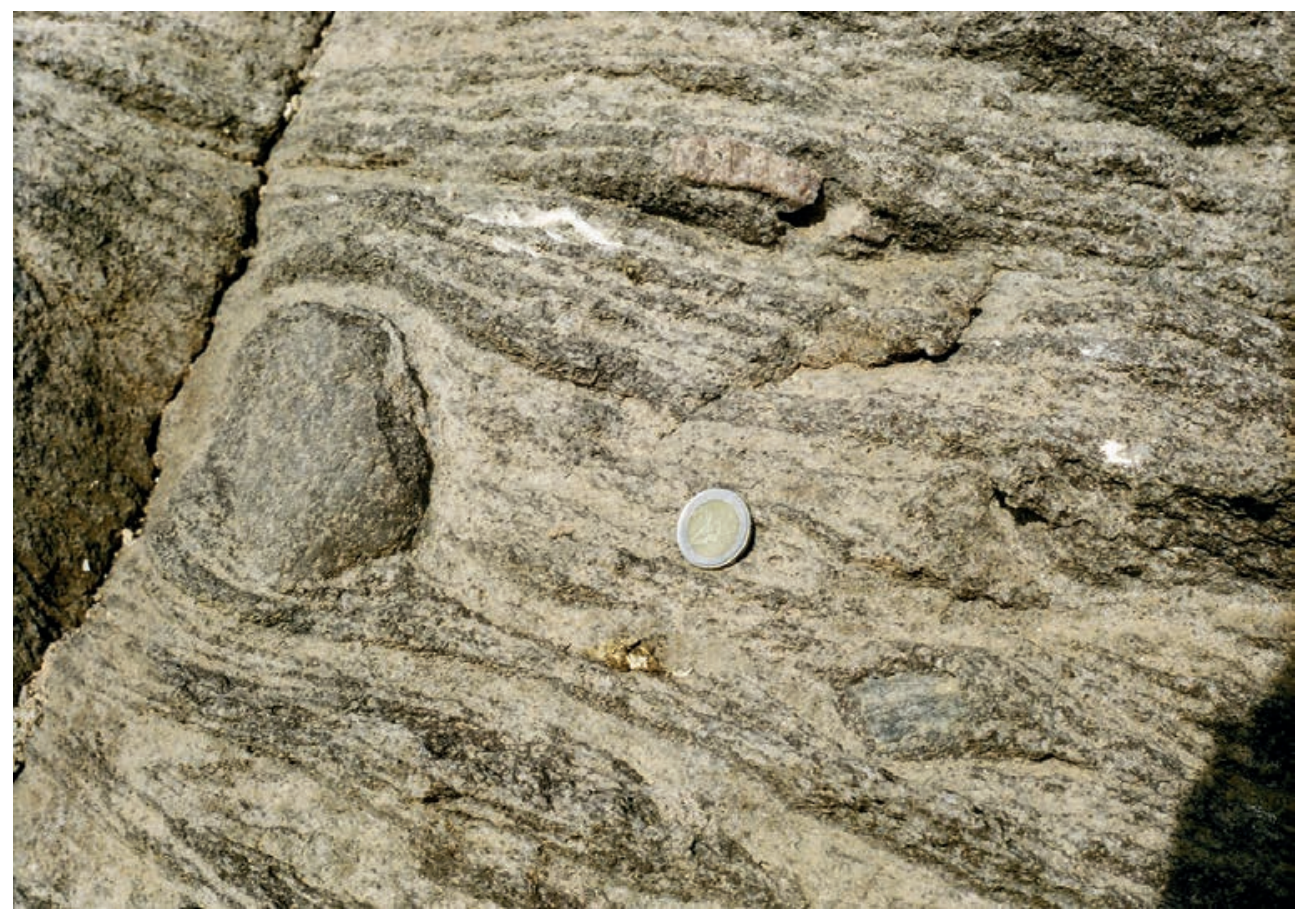

Andesitas de la isla del Rey, mostrando enclaves andesíticos (centro) y de venas silíceas (arriba), así como bandeado de flujo magmático.

En la isla de Isabel II, las orientaciones de los planos de flujo varían entre $\mathrm{N} 20^{\circ}-30^{\circ} \mathrm{O}$ con inclinaciones $15^{\circ}-30^{\circ} \mathrm{OSO}$, en la par te oriental, y N-S, subverticales, en la par te occidental de la misma. La disyunción columnar, no muy conspicua, se dispone de for ma perpendicular a los planos de flujo . Las orientaciones de estas estr ucturas parecen indicar que la costa oeste de la isla podría constituir, aproximadamente, el borde de la estructura domática.

En la isla del Rey, la orientación que presentan los planos de flujo magmático varía progresivamente, disponiéndose de forma paralela a la elongación arqueada que presenta la isla: así, en el norte de la misma se presentan con orientación $\mathrm{N} 45^{\circ}$ E e inclinación $20-25^{\circ} \mathrm{SE}$; en el centro, se orientan N-S y se inclinan $25^{\circ}$ - 
$30^{\circ} \mathrm{E}$; finalmente, en el sur insular, la orientación puede llegar a $\mathrm{N} 30^{\circ} \mathrm{O}$ y la inclinación a $50^{\circ}-60^{\circ}$ ENE. De la misma manera, la inclinación de la disyunción columnar varía progresivamente entre inclinaciones $65^{\circ}-70^{\circ} \mathrm{NO}$, en el norte de la isla, $60^{\circ}-65^{\circ} \mathrm{O}$ en el centro, y $30^{\circ}-40^{\circ} \mathrm{SO}$ en el sur. Todos estos datos parecen indicar que el borde deducible para el domo subvolcánico coincide, aproximadamente, con el borde oriental de la isla.

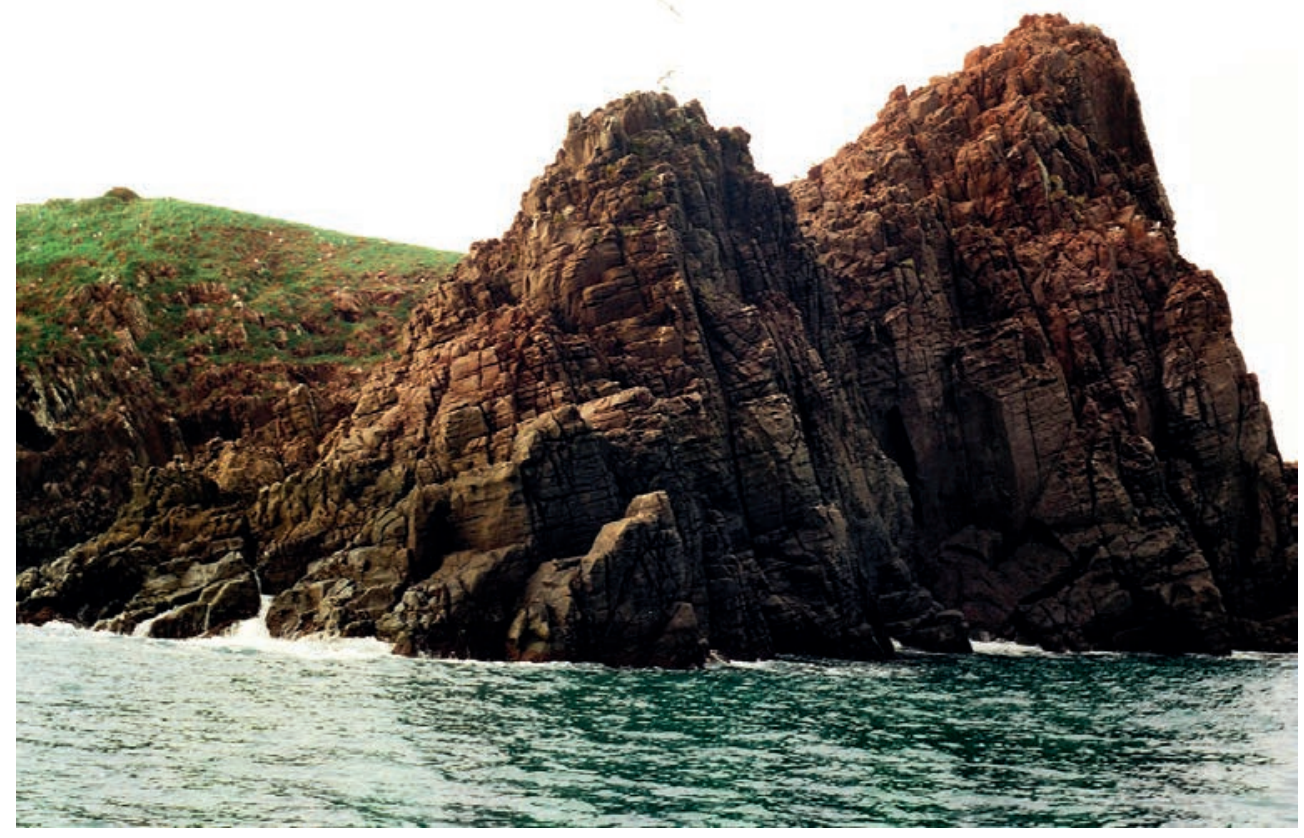

Andesitas del norte de la isla del Rey, mostrando bandeado magmático (superficies planares, poco inclinadas hacia la izquierda) y disyunción columnar grosera (planos menos frecuentes, fuertemente inclinados hacia la derecha).

En las islas de Isabel II (pr incipalmente en su par te nororiental) y, sobre todo, en la del Rey aparece, de forma generalizada, un sistema de venas silíceas orientadas $\mathrm{N} 20^{\circ}-60^{\circ} \mathrm{E}$, subverticales, de potencia decimétrico-métrica y estructura zonada. Estas venas están constituidas por sílice meso-micr ocristalina a opalina, de color ocre o amarillento, y a veces carbonato dolomítico-ankerítico, con diseminaciones de óxidos de Fe y de Mn; son de origen hidrotermal y están, pues, localizadas en la parte interna del domo, razón por la cual sólo se presentan en estas islas. 


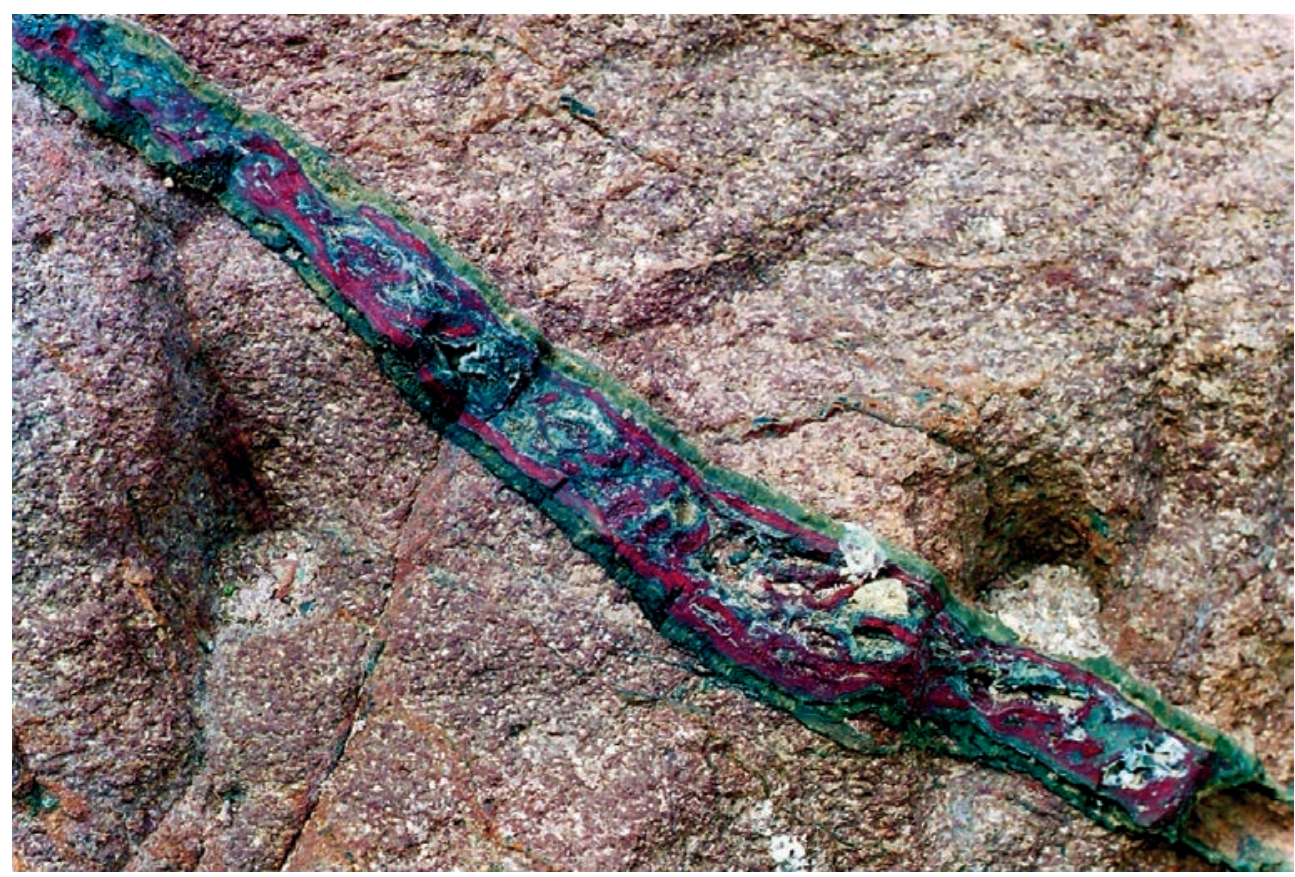

Vena silícea en las andesitas de la isla del Rey.

Finalmente, en la costa nor te de la isla de Isabel II apar ece una fractura distensiva de orientación NNE-SSO e inclinación $80^{\circ} \mathrm{E}$.

\section{El apilamiento alcalino de la isla del Congreso}

Los materiales de este Episodio se disponen discordantemente sobr e los calcoalcalinos del pitón de Punta de la Ermita. Son de naturaleza basáltica y forman un apilamiento tabular subhorizontal, de más de 35-40 m. de espesor, ligeramente inclinado al este, y hoy en día muy erosionado. El apilamiento estáconstituido, fundamentalmente, por niveles piroclástico-escoriáceos rojizos o grises, coladas basálticas oscuras y, al menos, una intercalación blanquecina de materiales finos.

Los niveles piroclástico-escoriáceos, de 0,5-8 m. de espesor, están constituidos por fragmentos basálticos $\mathrm{v}$ acuolares decimétricos y lapillis basálticos subredondeados, muy vesiculares, de 0,7-3 mm. de tamaño. Estos piroclastos pueden presentarse soldados entre sí o empastados en una matriz rojiza de grano fino.

Las coladas basálticas, de hasta 5-6 m. de espesor individual, son característicamente vacuolares. Las vacuolas presentan disposición alargada en el senti- 
do del flujo y pueden estar r ellenas de calcita. Petrográficamente, son basaltos olivínicos microporfídicos y microcristalinos, vesiculares y fluidales, en los que destacan fenocristales prismáticos de plagioclasa (0,7-1,1 mm.) y, en menor proporción, de clinopiroxeno, en una matriz microcristalina rica en los minerales citados. Los olivinos, muy iddingsitizados, son abundantes pero de menor tamaño que los anteriores.

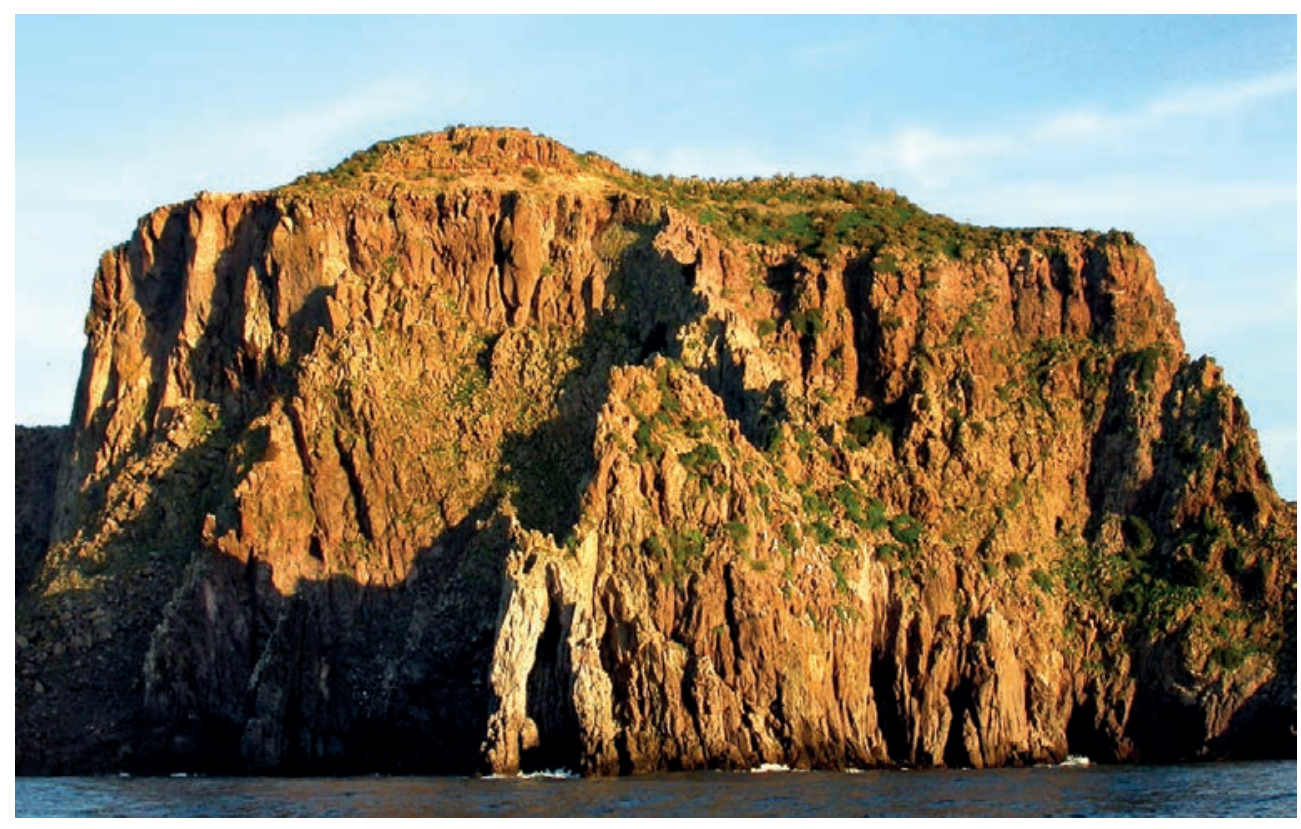

El apilamiento tabular basáltico alcalino, de la parte alta de la isla del Congreso, discordante sobre los materiales calcoalcalinos del pitón de Punta de la Ermita.

El nivel blanquecino de materiales finos, de 1,5 m. de espesor debe representar un depósito hidr omagmático, por sus características petr ográficas. Son tobas hidrovolcánicas que se pr esentan en niveles muy compactos, de espesor individual decimétrico-centimétrico, con fragmentos decimétr icos basáltico vacuolares, soldados entre sí o empastados en una matriz amarillento-gris-rojiza, de grano fino o cr iptocristalina, constituida por esquirlas vítr eas muy vesiculares, con incipientes acículas de plagioclasa. La presencia de este nivel, a unos $125 \mathrm{~m}$. de altitud, plantea que el nivel del mar plioceno debía estar más alto que el actual. 
El apilamiento de materiales alcalinos es cor tado por un dique basáltico subvertical, de dirección norteada y varios metros de espesor, que forma la parte apical de la isla. La roca es gris oscuro, de grano fino, lajeada en el contacto y no vacuolar.

Además de los materiales descritos, hay diques basálticos de color negro o verde oscuro, de direcciones variables entre $\mathrm{N} 30^{\circ}$ y N80 $\mathrm{E}$, subverticales y de espesor métrico, que cortan los materiales calcoalcalinos y que se supone son, en parte, los conductos de alimentación de las coladas y niv eles piroclásticoescoriáceos del apilamiento. Pueden obser varse en diversos puntos de la isla, tales como las Cuevas, las Cuevas de Lara y, el más accesible, en la ladera oriental de playa Larga.

Los materiales basálticos del apilamiento alcalino , de edad pr obable pliocena, son los últimos emitidos por los antiguos volcanes de las Chafarinas.

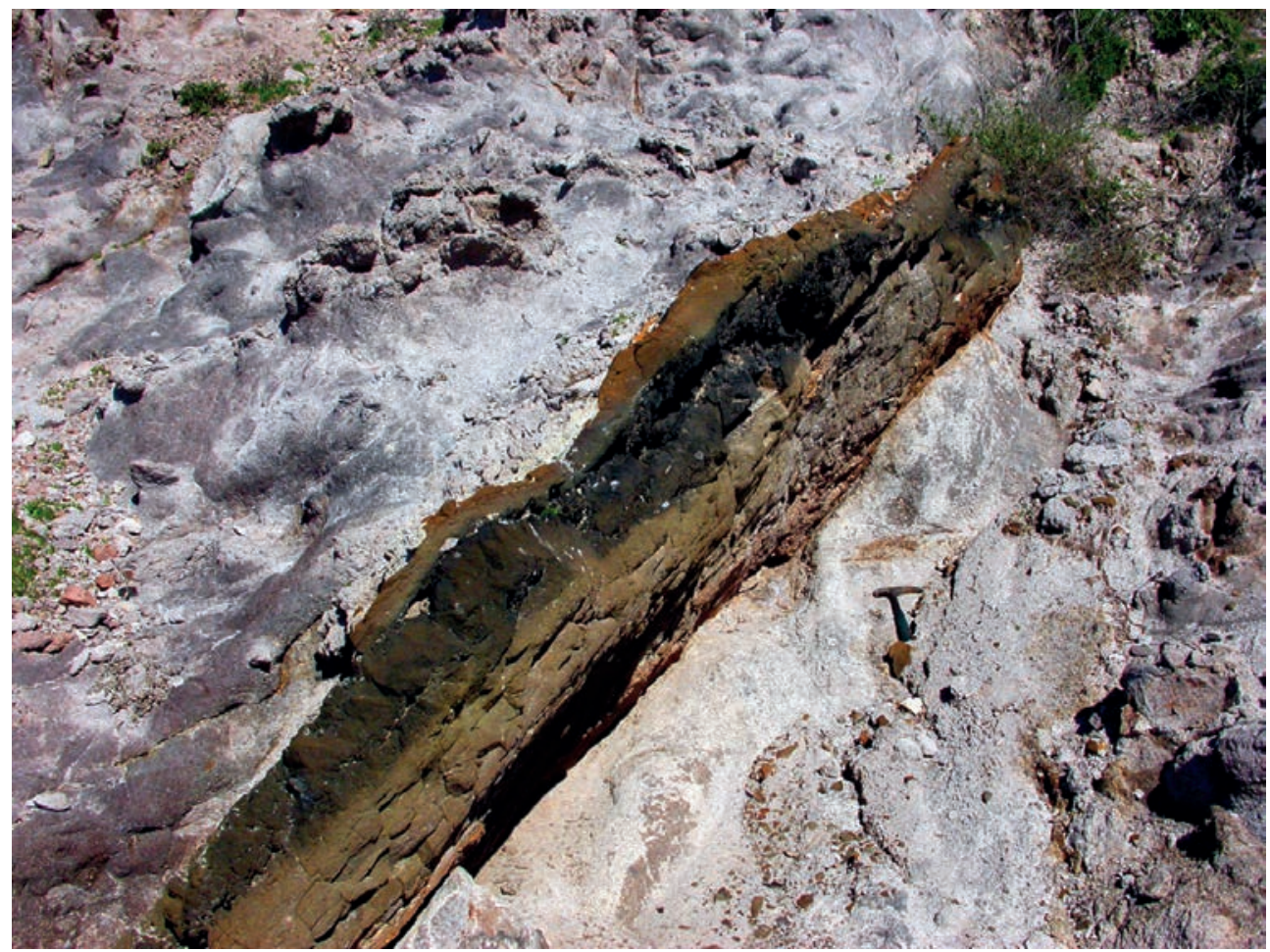

Dique basáltico alcalino, encajando en materiales de la Unidad inferior calcoalcalina. Laderas sobre playa Larga. 


\section{Los depósitos sedimentarios de las Chafarinas}

En este capítulo se describirán los materiales sedimentarios presentes en las islas, de edad cuaternaria, divididos en dos grandes grupos: los de las laderas altas (antiguos) y los de los litorales (recientes o actuales).

\section{El tapiz sedimentario de las laderas altas}

El tapiz sedimentario de estas antiguas superficies está constituido por depósitos de ladera (la litología dominante), costras calcáreas y arenas eólicas. En algunos lugares, tal como en la parte central de la isla del Rey y en la de Isabel II (junto al puerto), estas litologías pueden alter nar, conformando series estratigráficas de espesor métrico o casi decamétrico; aunque, para estos casos concretos, más que de tapiz debería hablarse de cobertera sedimentaria.

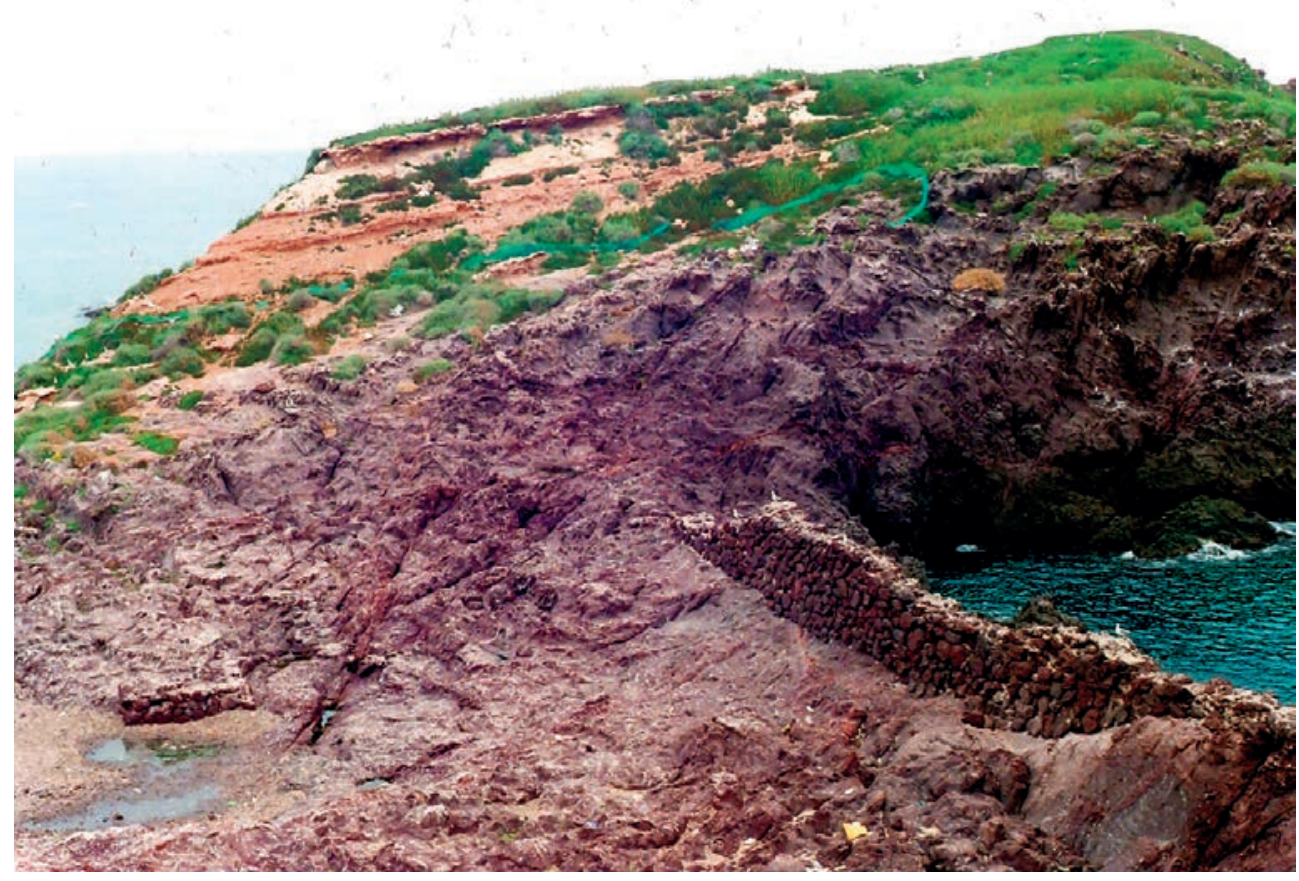

La cobertera sedimentaria de la parte central de la isla del Rey, dispuesta discordantemente sobre andesitas. Se distinguen depósitos de ladera limosos, con cantos (tonos marrones, en la parte baja), arenas eólicas (nivel amarillento superior) y costras calcáreas (resaltes duros, blanquecinos). 


\section{Los depósitos de ladera}

Los depósitos de ladera alcanzan su mayor extensión en la isla del Congreso, donde constituyen la única litología del tapiz,con un espesor máximo de unos $4 \mathrm{~m}$. Son de naturaleza limo-arcillosa, con gasterópodos continentales (Helix) y cantos volcánicos de tamaño deci-centimétrico, subangulosos a subredondeados, en proporciones variables. Su color es marrón o gris, dependiendo de su mayor o menor proporción en matriz limo-arcillosa. Pueden presentarse afectados por calidificación (costras en enrejado), sobre todo en los lugares de menor pendiente.

En las islas de Isabel II y del Re y, los depósitos de ladera suelen tener menor proporción de cantos y forman niveles alternantes con las otras litologías (costras calcáreas y arenas eólicas).

\section{Las costras calcáreas}

Las costras calcáreas alcanzan su mayor desarrollo en la isla del Rey, donde existen dos niveles en la sucesión sedimentar ia de la parte central insular, dispuesta sobre las r ocas volcánicas calichificadas. El nivel inferior tiene unos 70 $\mathrm{cm}$. de espesor y se presenta intercalado en dicha sucesión. El nivel superior, de unos 0,5 m. de espesor, corona y rebasa la misma, recubriendo gran parte de la superficie insular directamente sobre las rocas volcánicas. Ambos niveles suelen ser pulverulentos hacia muro y bandeados hacia tec ho, con cantos andesíticos dispersos.

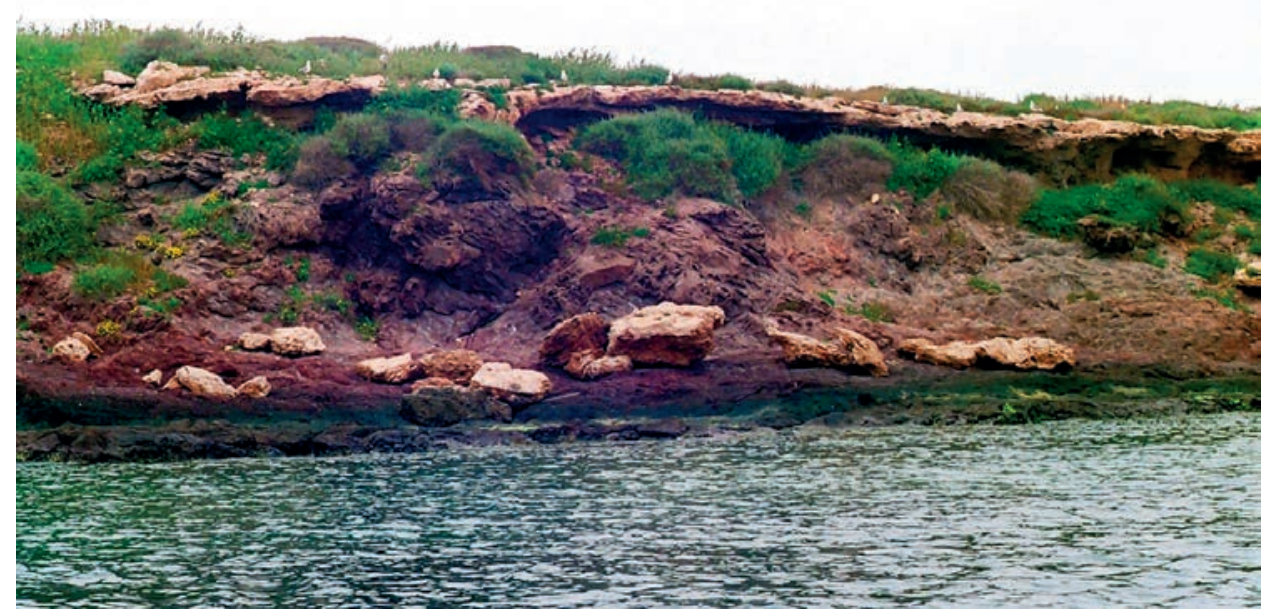

Nivel de costra calcárea, sobre andesitas. Costa suroccidental de la isla del Rey. 
Existen dataciones de edades absolutas de ambas costras y de la calichificación del sustrato volcánico (Rodríguez Vidal et al., 1999). Para la inferior, una datación mediante isótopos de uranio indica una edad de $86,2+-1 \mathrm{Ka}$ BP. Para la superior, otra mediante isótopos de carbono indica 20,3 +- 0,3 Ka BP. Para la calichicación del sustrato volcánico, una datación mediante isótopos de uranio indica una edad poco acorde con las anterior mente citadas: 22,4 +1,8 Ka BP.

En Isabel II, las costras se presentan en su parte suroriental. Generalmente, hay un único niv el, desarrollado sobre el sustrato volcánico, aunque localmente (junto al puer to) puede existir una sucesión cua ternaria similar a la del Rey, con más de un nivel discontinuo de costra.

\section{Las arenas eólicas}

En la isla del Rey forman un tramo de unos $3 \mathrm{~m}$. de espesor, localizado en la parte alta de la sucesión sedimentar ia. Las arenas son de g rano medio-fino, amarillentas, bastante homogéneas y con abundantes restos fósiles de gasterópodos continentales, estando constituídas por microorganismos carbonatados y/o fragmentos de conchas $(85 \%)$ y cuarzo $(10 \%)$, de procedencia litoral (¿continental?) así como, accesoriamente, minerales volcánicos de las islas. Para este tramo, existe una datación de edad absoluta (RodríguezVidal et al., 1999), realizada mediante aminoácidos e isótopos de carbono, en conchas de gasterópodos. La edad obtenida es superior a $40 \mathrm{Ka}$ BP.

En Isabel II, el tramo arenoso es menos potente, de unos 0,5 m. de espesor, localizándose en la parte superior de la sucesión sedimentaria junto al puerto.

\section{Los depósitos litorales}

Los depósitos litorales están relacionados con la erosión actual, centrada en el modelado de los acantilados (o de las fuer tes laderas litorales) que cortan abruptamente la suave morfología alta y confor man los actuales perímetros de las islas. Estos depósitos se localizan, pues, por debajo de la cota de aparición de las laderas altas y, en cuanto a su or igen pueden ser de g ravedad (coluviones y canchales de desprendimiento) o de retrabajado litoral (playas).

\section{Los coluviones}

Los coluviones más extensos, constituidos por cantos y boques volcánicos en una escasa ma triz areno-limosa, se presentan sólo en la isla del Cong reso, 
junto a las playas más importantes de la isla (playa Larga, en el sur, y playa de la Sangre, en el noroeste).

\section{Los canchales de desprendimientos}

También se presentan únicamente en la isla del Congreso, la isla de ma yor relieve, donde el más impor tante forma una notable acumulación litoral cónica, de 150 por $80 \mathrm{~m}$. de extensión emerg ida y $45 \mathrm{~m}$. de altura, al pie de un acantilado vertical de unos $115 \mathrm{~m}$. de altura. El depósito, constituido por bloques métricos o mayores, sin matriz, se forma a partir de desprendimientos favorecidos por la disyunción columnar y el diaclasado de la litología volcánica (pitón de Punta de la Ermita), sin descartar que haya podido haber derrumbes masivos de la misma.

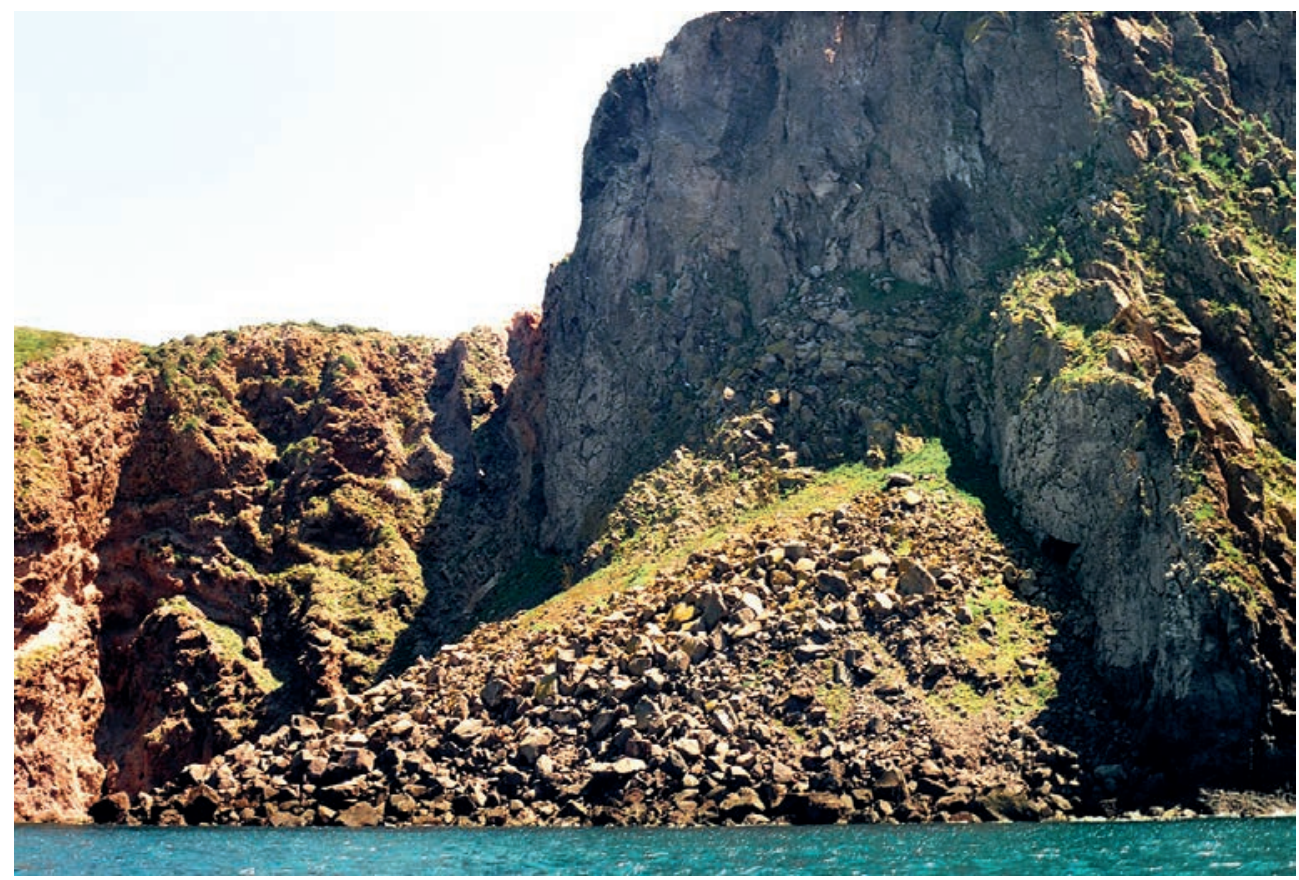

Canchal de desprendimientos en la costa occidental de la isla del Congreso, al pie de un acantilado tallado en el pitón de Punta de la Ermita.

Depósitos semejantes, pero más pequeños y al pie de pardes menos altas, se encuentran en los extremos occidental y oriental de playa Larga, en el sur del Congreso. 


\section{Las playas}

Las playas son escasas y de fuer te pendiente, como cabe esperar de unas islas cuyo perímetro es generalizadamente acantilado. Están constituidas por gravas $\mathrm{y}$, a veces, bloques subredondeados, y arenas muy minoritarias o ausentes.

En su mayor parte, las gravas proceden del retrabajamiento de bloques desprendidos o de coluviones, siendo ésta la razón por la cual el Congreso, la isla de más relieve, es la que suele contener playas, de 250-100 m. de longitud máxima y 20-10 m. de anchura (playas Larga y de la Sangre, respectivamente).

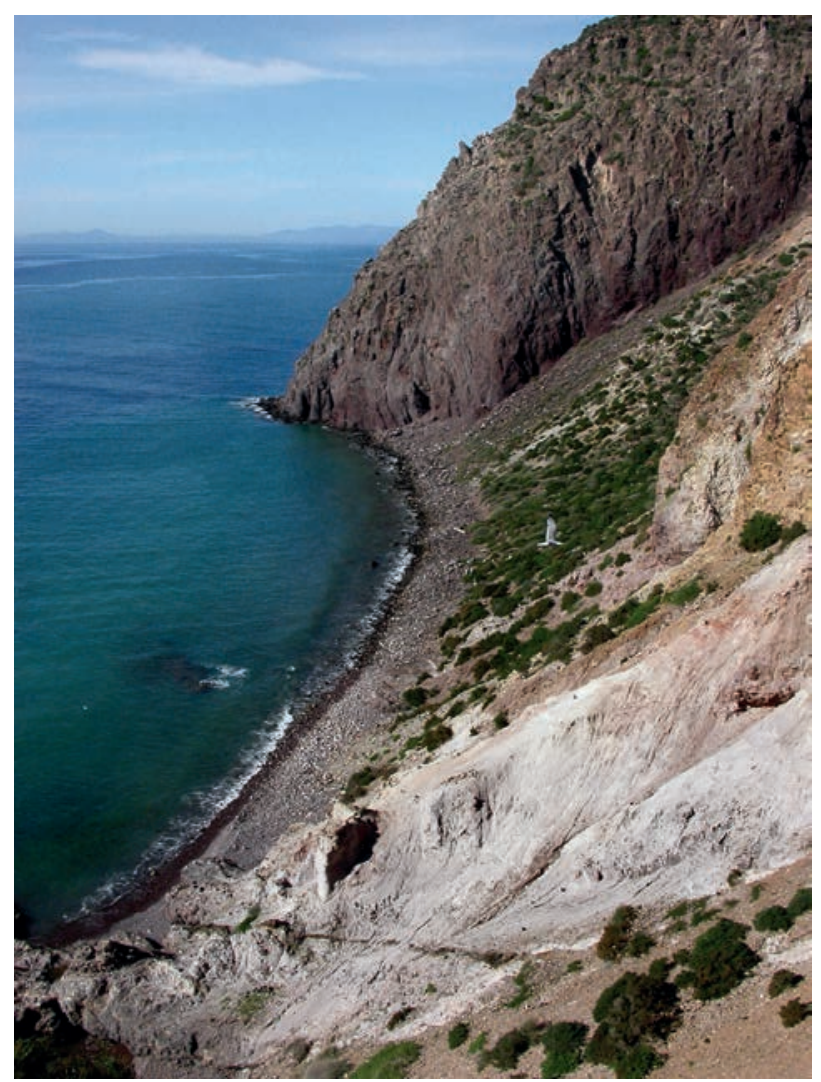

Playa Larga, en la costa suroccidental de la isla del Congreso.

Las islas de Isabel II y del Re sólo tienen una pequeña playa cada una, de 20$40 \mathrm{~m}$. de longitud, y 10-20 m. de anchura. Se localizan inmediatamente al sur de los restos del dique que unía ambas islas por lo que sus gravas pueden provenir de dichos restos. 


\section{Historia geológica de las islas}

El relieve de las islas fue generado como consecuencia de apilamientos progresivos de materiales volcánicos (fase de volcanismo activo), encima de los puntos de salida de los mismos: es el proceso de crecimiento volcánico. Pero, como todo relieve terrestre, las islas están sometidas a procesos de erosión que reducen progresivamente su tamaño, tanto en altitud como en extensión, y de forma más notoria cuando el volcanismo es inactivo.

A partir de los datos geológicos regionales, de la disposición de los materiales de las islas, y de la morfología que actualmente presentan, puede reconstruirse la historia geológica de las mismas, en la que los procesos de crecimiento volcánico y las fases erosivas, siempre en conflicto, han alternado en el tiempo.

\section{Nacimiento y primera etapa (calcoalcalina) de crecimiento volcánico}

Según los datos de edades absolutas para rocas volcánicas semejantes del entorno norteafricano, puede suponerse que el volcanismo calcoalcalino que da lugar a las islas se inicia hace aproximadamente 9-8 millones de años, edad que podrá ser precisada cuando existan dataciones propias de las rocas de las islas.

Esta etapa de crecimiento volcánico se realiza mediante la combinación de un apilamiento externo de materiales emitidos (unidades calcoalcalinas inferior y superior, de la isla del Congreso) y el emplazamiento poco profundo, a veces en los propios materiales apilados, de masas intr usivas domáticas (rocas de las islas de Isabel II y del Re, e intrusivo de Punta de la Emita, en la del Congreso). La naturaleza viscosa de las la vas calcoalcalinas tiende a for mar acumulaciones (domos) encima del punto de salida,cuyo colapso o explosión posteriores generan las facies de brechas del apilamiento.

Pueden deducirse, al menos, dos puntos de salida píncipales del volcanismo calcoalcalino: uno al oeste del Cong reso y otro en la zona Isabel II-Re y. Por coalescencia de emisiones, es posible que en esta etapa se llegara a for mar un único edificio volcánico, quizá de unos $800-1.000 \mathrm{~m}$. de altura mínima. Este edificio estaría localizado en las cercanías de la costa, bien fuera constituyendo un promontorio de la misma o un relieve insular.

\section{Primera fase erosiva (post-calcoalcalina)}

El volcanismo calcoalcalino debió cesar hace unos 7,5 millones de años, iniciándose a partir de entonces una etapa de destrucción erosiva sobre el edificio volcánico. 
Al final de esta etapa de desgaste, el edificio volcánico calcoalcalino podría tener alturas probablemente no superiores a los 100 m., y constituir, quizá, dos edificios insulares (uno en el Congreso y otro en Isabel II-Rey).

\section{Segunda etapa (alcalina) de crecimiento volcánico}

La reanudación del volcanismo, ahora alcalino, se debió iniciar hace unos 5-3 millones de años (fundamentalmente, en el Plioceno). La etapa de cr ecimiento volcánico alcalino se verificó mediante el apilamiento tabular de coladas, de naturaleza más fluida que la de las calcoalcalinas, y niveles piroclásticos.

Para esta etapa de crecimiento se deduce la existencia de un probable único punto de emisión, localizado al oeste de la isla del Congreso. La singularidad del punto y el pr obable menor volumen de materiales emitidos, debieron dar lugar a un crecimiento centrado solo sobre esta isla que debió alcanzar una altura no mayor de 125-250 m. respecto a la que actualmente pr esenta. Aunque la presencia del nivel hidromagmático, a $125 \mathrm{~m}$. de altura sobre el nivel del mar actual, podría indicar que el niv el del mar plioceno estaba considerab lemente más alto que el actual.

$\mathrm{Si}$, como parece, la etapa de crecimiento alcalino se focalizó sólo en la isla del Congreso, los relieves correspondientes a las futuras islas de Isabel II y Rey habrían seguido estando sometidos a erosión.

\section{Segunda fase erosiva (post-volcánica)}

El volcanismo alcalino debió cesar hace unos 2-1 millones de años. Desde entonces se generó una fase erosiva que condujo primeramente a la for mación de los suaves relieves de las partes altas de las islas y, finalmente, a la generación de los abruptos litorales actuales. Entre ambos hitos existió la posibilidad de una conexión física entre las islas y la costa nor teafricana, conexión que quizá ha persistido hasta épocas relativamente recientes.

\section{Los suaves relieves superiores}

La reconstrucción morfométrica de estos relieves indica ya la existencia de tres edificios correspondientes a las actuales tr es islas, pero algo más extensos hacia el exterior del archipiélago, sobre todo hacia el oeste del Congreso y el este del Rey.

La datación de algunas litologías sedimentarias asociadas a dichos relieves, indica una edad variable, pero no menor de 20.000 años, para su fase final de elaboración. 


\section{La posible conexión física entre las islas y la costa norteafricana}

Por sus características de r elativamente débiles pendientes, y por la importancia del tapiz sedimentar io asociado, es posible que los r elieves antiguos descritos se hayan generado en relación con un nivel de base mar ino más bajo que el actual, lo que implica que, quizá en esta época, había una conexión física entre las islas y la costa norteafricana.

Posteriormente, habrían tenido lugar la elevación del nivel de base marino (transgresión flandriense) y la desaparición de la conexión, quizá por dinámica erosiva litoral, siendo una hipótesis sugestiv a (por demostrar) el que las islas estuviesen todavía unidas a la costa, hace unos 7.000 años, durante la época del poblamiento neolítico de Zafrín, en el Congreso.

En efecto, la gran dificultad para un poblamiento insular, debido al reducido espacio y a la escasez de recursos, sin ni siquiera agua potable propia, así como la presencia de restos de fauna continental (antílope, cabra, etc.) no autóctona de las islas en Zafrín, sugieren que, durante esta época, las islas podrían haber constituido un cabo o promontorio estratégico en la costa norteafricana.

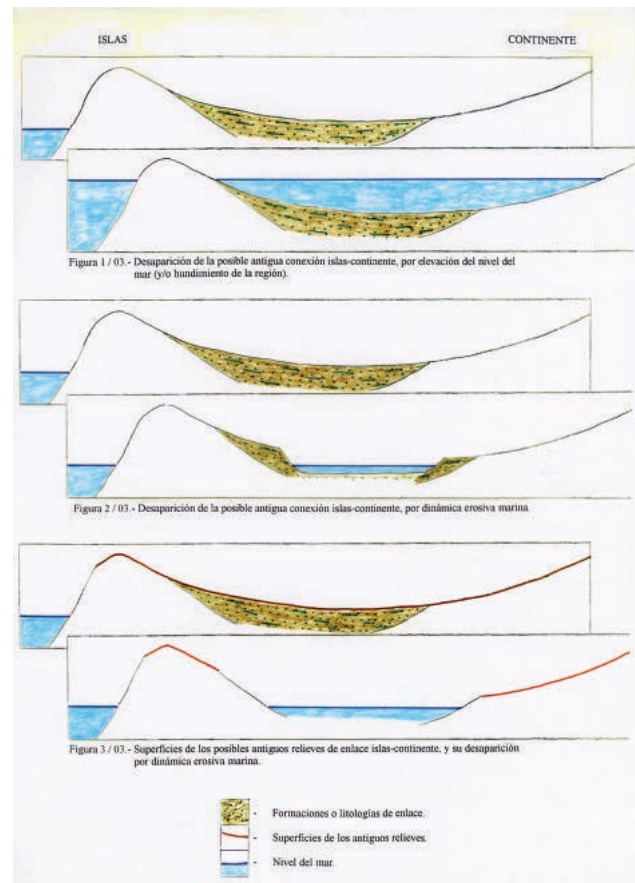

Evolución de la conexión de enlace islas-continente hasta su desaparición por dinámica erosiva marina (A. Pineda). 
Desde el punto de vista geológico y fisiográfico, hay datos que abundan en dicha posibilidad de conexión, tales como la existencia de bajos fondos entre las islas y la costa, la propia existencia del cabo delAgua como promontorio costero apuntando a las mismas, y el contorno cartográfico cóncavo del litoral, a ambos lados del cabo.

Si se tiene en cuenta la gran extensión de los depósitos dunares y playeros en el área del cabo del Agua, la conexión podría haber consistido, fundamentalmente, en un antiguo tómbolo arenoso, cuya destrucción posterior por la dinámica litoral, habría dado lugar a los mđeriales que han nutrido dichos depósitos. La demostración de esta hipótesis exigiría estudios petrográficos y mineralógicos de las arenas del entorno del cabo y de las islas (para ver si contienen elementos de procedencia volcánica o continental, respectivamente), así como dataciones absolutas para las dunas del cabo.

\section{La erosión actual}

En la actualidad, las islas se encuentran sometidas fundamentalmente a un proceso erosivo "lateral", debido a la mayor importancia de la dinámica litoral, que tiende a generar acantilados. El soca vamiento basal de los acantilados da lugar a la inestabilidad creciente de los mismos y a su derumbe posterior, lo que a la larga significa un retroceso costero generalizado que tiende a educir progresivamente los perímetros y áreas insulares, formándose una pequeña rasa marina ante las mismas.

\section{BIBLIOGRAFÍA}

ALONSO, F. M., CÁCERES,L. M., CLEMENTE,L., GARCÍA FERNÁNDEZ, L.V., MARAÑÓN, T., OJEDA, F. y RODRÍGUEZVIDAL, J. (1998). Estudio del medio físico y vegetación de las Islas Chafarinas. Informe inédito.

ANDRIEUX, J., FONTBOTÉ, M. y MATTAUER, M. (1971). "Sur un modèle explicatif de l'Arc de Gibraltar”.Earth and Planetary Sc.Let., 12 (2), 191-198. ARAÑA, V. y VEGAS, R. (1974). "Plate tectonics and volcanism in the Gibraltar Arc.". Tectonophysics, 24, 197-212.

BARRERA, J. L. y PINEDA, A. (2006). "Islas Chafarinas. La Geología de un archipiélago deseado por todos”. Tierra y Tecnología, 30 (2 Semestre), 1330. Ilustre Colegio Oficial de Geólogos. Madrid. 
BELLON, H. (1976). Séries magmatiques néogènes et quaternaires du portour de la Méditerranée occidentale comparées dans leur cade géochronométrica; implications géodynamiques. Thése Univ. Paris Sud (Orsay), 367 p.

BRAVO, A. y BELLVER, J.A. (2002). "Descubierto un poblado neolítico del V milenio antes de Cristo en las Islas Chaf arinas". Ambienta (Ministerio de Medio Ambiente), 8, 12-14.

CALDERÓN, S. (1894). "Las Chafarinas". Anales de la SEHN, 23, 303-316.

DELARUE, Ch., y BROUSSE, R. (1974). "Volcanisme miocène en subduction au Maroc á l'extremité orientale de l'Arc de Gibraltar”. Comp. Rend. de l'Acad. Sc. Paris, 279, 971-974.

EL BAKKAli, S., GOURGAUD, A., BOURDIER, J. L., BELLON, H. y GUNDOGDU, N. (1998). "Post-collision neogene volcanism of the Eastem Rif (Morocco). Magmatic evolution through time”. Lithos, 45, 523-543.

FALLOT, P. y MARÍN, A. (1939). "La Cordillera del Rif (tomos I y II)".Memorias del Inst. Geol. Min. España, XLIII.

FERNÁNDEZ NAVARRO, L. (1908). "Datos geológicos acerca de las Posesiones Españolas del Nor te de África”. Soc. Española de Hist. Nat., Mem., 5, 259-340.

HERNÁNDEZ, J. (1983). Le volcanisme miocène du Rif Oriental (Maroc). Thèse Sciences, ParisVI (P. et M. Curie), 2 vols., 590 p.

HERNANDEZ, J. y BELLON, H. (1985). “Chronologie K- Ar du volcanisme miocène du Rif Or iental (Maroc): implications tectoniques et magmatologiques”. Rev. Géol. Dyn. et Géog. Phys., 26 (2), 85-94.

LÓPEZ RUIZ, J. y RODRÍGUEZ BADIOLA, E. (1980). "La región volcánica neógena del Sureste de España”. Estudios Geológicos, 36, 5-63.

MARÍN, A. (1921). "Nota geológica de las islas Chafarinas". Boletín del Instituto Geológico de España. II, $3^{\text {a }}$ serie, 224-241.

OLIVET, J. L., AUZENDE, J. M. y BONNIN, J. (1973). "Structure et evolution tectonique du bassin d'Alboran”. Bull. Soc. Geol. Fr., (7), 15, 108-112.

PINEDA, A. (1985). "Las Zonas Internas y Externas Béticas como partes meridionales de la Placa Ibér ica: una nueva interpretación para el área límite atlántico-mediterránea”. Stvd. Geol. Salmant., XXI, 87-113.

PINEDA, A. y BARRERA, J.L. (2003). Mapa Geólogico (escala 1/5.000) y Memoria Explicativa de las Islas Chafarinas (inédito). Proyecto MAGNA, IGME.

PINEDA, A. y BARRERA, J. L. (2004). "El volcanismo neógeno de las islas 
Chafarinas, mar Mediterráneo (N África, España).VI Congreso Geológico de España, Zaragoza”. Geotemas, 6 (1), 167-170.

RODRIGUEZ VIDAL, J., CACERES, L.M., ALONSO CHAVES, F.M. y RODRIGUEZ RAMIREZ, A. (1999). "El Cuaternario en las Islas Chafarinas (Norte de África)”. Avances en el Estudio del Cua ternario Español. Lluís Pallí Buxó-Carles Roqué Pau (eds.), Girona, 195-200.

RODRÍGUEZ VIDAL, J., CÁCERES, L. M., MARTÍNEZ AGUIRRRE, A., AlCARÁZ, J., M. BELlOUMini, G., AlOnSO CHAVES, F. M., RODRÍGUEZ RAMÍREZ, A. y CANTANO, A. (2000). "Dataciones isotópicas de carbonatos continentales en el Pleistoceno super ior de las Islas Chafarinas (N África, España)”. Cuaternario y Geomorfología, 14 (3-4), 101-108.

VALLE DE LERSUNDI, A. Del (1927). “Nota acerca de la formación geológica de la región de Cabo delAgua (Zona oriental del Protectorado Español en Marruecos)”. Boletín del Instituto Geológico y Minero de España, XLIX, 321-339.

VÈLAIN, Ch. (1874). "Constitution geológique des îles v oisines du litoral de l'Afrique”. Comp. Rend. de l'Acad. Sc., Paris, LXVIII, 70-74. 